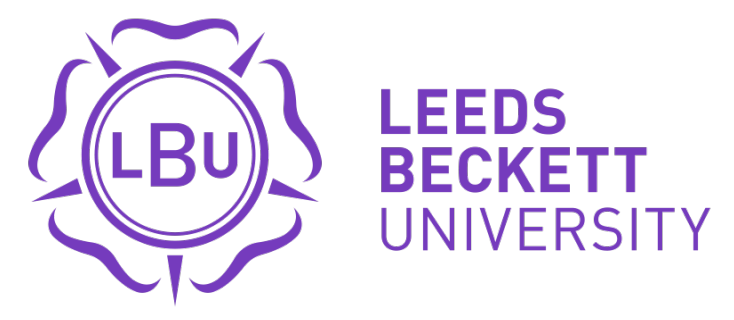

Citation:

Vajpayee, $\mathrm{V}$ and Becerra, $\mathrm{V}$ and Bausch, $\mathrm{N}$ and Deng, $\mathrm{J}$ and Shimith, SR and Arul, AJ (2021) Robust-optimal integrated control design technique for a pressurized water-type nuclear power plant. Progress in Nuclear Energy, 131. p. 103575. ISSN 0149-1970 DOI: https://doi.org/10.1016/j.pnucene.2020.103575

Link to Leeds Beckett Repository record:

https://eprints.leedsbeckett.ac.uk/id/eprint/7372/

Document Version:

Article (Accepted Version)

Creative Commons: Attribution-Noncommercial-No Derivative Works 4.0

The aim of the Leeds Beckett Repository is to provide open access to our research, as required by funder policies and permitted by publishers and copyright law.

The Leeds Beckett repository holds a wide range of publications, each of which has been checked for copyright and the relevant embargo period has been applied by the Research Services team.

We operate on a standard take-down policy. If you are the author or publisher of an output and you would like it removed from the repository, please contact us and we will investigate on a case-by-case basis.

Each thesis in the repository has been cleared where necessary by the author for third party copyright. If you would like a thesis to be removed from the repository or believe there is an issue with copyright, please contact us on openaccess@leedsbeckett.ac.uk and we will investigate on a case-by-case basis. 


\title{
Robust-Optimal Integrated Control Design Technique for a Pressurized Water-type Nuclear Power Plant
}

\author{
Vineet Vajpayee, Victor Becerra, Nils Bausch, Jiamei Deng, S. R. Shimjith, A. John Arul
}

\begin{abstract}
A control design scheme is formulated for a pressurized water type nuclear power plant by integrating the optimal linear quadratic Gaussian (LQG) control with the robust integral sliding mode (ISM) technique. A novel robust-optimal hybrid control scheme is further proposed by integrating the LQG-ISM technique with the loop transfer recovery approach to enhance the effectiveness and robustness capability. The control architecture offers robust performance with minimum control efforts and tracks the reference set-point effectively in the presence of disturbances. The multi-input-multi-output nuclear power plant model adopted in this work is characterized by 40 state variables. The nonlinear plant model is linearised around steady-state operating conditions to obtain a linear model for controller design. The efficacy of proposed controllers is demonstrated by simulations on different subsystems of the nuclear power plant. The control performance of the proposed technique is compared with other classical control design schemes. Statistical measures are employed to quantitatively analyse and compare the performance of the different controllers that are studied in the work.
\end{abstract}

Index Terms-Optimal Control, Robust Control, Pressurized Water Reactor, Nuclear Power Plant.

\section{INTRODUCTION}

Nuclear power plants (NPPs) are complex non-linear systems. Control of NPPs pose challenges due to parameter variations caused by fuel burn-up, internal reactivity feedbacks, modelling uncertainties, and unknown disturbances. System parameters associated with reactor core, thermal-hydraulics, reactivity feedbacks, etc., differ significantly with operating conditions. The routine load cycles over a broad range of power variations can significantly affect plant performance. Uncertainties in the actuator signals and noisy sensor measurements add further complexities to the control design problem. Consequently, traditional controllers often fail to deliver desirable performance. The plant control systems must be able to respond promptly and safely to fast variations in demand in an uncertain environment. Thus, it is essential to develop

Vineet Vajpayee (vineet.vajpayee@port.ac.uk), Victor Becerra (victor.becerra@port.ac.uk), and Nils Bausch (nils.bausch@port.ac.uk) are with School of Energy and Electronic Engineering, University of Portsmouth, Portsmouth, PO1 3DJ, United Kingdom.

Jiamei Deng (j.deng@leedsbeckett.ac.uk) is with School of Built Environment, Engineering, and Computing, Leeds Beckett University, Leeds, LS6 3QS, United Kingdom.

S. R. Shimjith (srshim@barc.gov.in) is with Reactor Control System Design Section, Bhabha Atomic Research Centre, Mumbai, 400 085, India and Homi Bhabha National Institute, Mumbai, 400 094, India.

A. John Arul (arul@igcar.gov.in) is with Probabilistic Safety, Reactor Shielding and Nuclear Data Section, Indira Gandhi Centre for Atomic Research, Kalpakkam, 603 102, India. improved control techniques which can provide closed-loop stability and enhance the safety and operability of NPPs.

A considerable amount of research has been done on the application of robust control techniques in nuclear reactors, especially for the core power control. In the last two decades, various control design techniques such as state feedback assisted control (SFAC) [1]-[5], $\mathcal{H}_{\infty}$ control [6][9], model predictive control (MPC) [10]-[14], sliding mode control (SMC) [15]-[21], and soft-computing based controls [22]-[27] have been proposed to deal with disturbances and uncertainties in NPPs. Edwards et al. [1] proposed the idea of SFAC to enhance the stability of the classical control loop by integrating a state-feedback compensating loop. Loop transfer recovery (LTR) technique has been combined with linear quadratic Gaussian (LQG) control in an SFAC framework for the improvement of reactor temperature and power controls during variation in reactor parameters [2]-[5]. $\mathcal{H}_{\infty}$-based control schemes have been designed for reactor power control and to obtain enhanced robustness over the classical LQG control scheme [6]-[9]. To deal with system design constraints in an uncertain NPP system, receding horizon-based robust MPC approaches, which solve an optimization problem at each sampling instant, have been proposed [10]-[14]. SMC is another robust control design technique applied to study the load-following problem of nuclear reactors. SMC guarantees robustness to the uncertainties entering through the input channel, once the system reaches the sliding manifold [15][21]. However, its implementation is sensitive to uncertainties during the reaching phase. To avoid this, an integral sliding mode approach has been proposed in the literature which enforces the system trajectories to lie on the sliding manifold from the very beginning thereby avoiding the reaching phase [28]. To deal with modelling uncertainties and disturbances, soft-computing techniques have been further incorporated in the controller design. Robust PID controller [22], fractionalorder PID controllers [23], neural network controllers [24], emotional controllers [25], fuzzy logic controllers [26], and genetic algorithms optimized controllers [27] have been proposed to enhance the capabilities of the classical controllers.

Generally, a robust controller often has to spend high control energy to achieve satisfactory performance in an uncertain environment, which may sometimes lead to saturation of actuators. Practically, a robust control strategy which spends less control energy is desired. This stimulus leads to the advancement of hybrid control strategies by integrating robust control with optimal control techniques [20], [21], [29], [30]. 
SMC has been combined with optimal control to deisgn core power control under the assumption that the complete state information is available for control design [20], [21]. However, for instance, the concentration of delayed neutron precursors is not directly measurable in a reactor. Thus, a state estimator is required to estimate the unmeasurable states and to design the state feedback control strategy [17], [19].

In this paper, a new control strategy for a PWR-type NPP is proposed by combining the optimal LQG control and the robust integral sliding mode (ISM) design approaches. The proposed LQG-ISM technique consists of the combined actions of a nominal controller and a discontinuous controller. The nominal controller uses the LQG approach, which involves a linear quadratic tracker (LQT) for state feedback control and a Kalman filter for states estimation. On the other hand, the discontinuous control employs the ISM approach, which allows the system motion to be invariant to disturbances throughout the entire system response. This paper further proposes a robust-optimal hybrid control strategy by integrating the LQG-ISM control with the LTR technique. The overall architecture thus offers enhanced robustness with improved system performance in the presence of uncertainties and disturbances.

In the NPP control design literature, the coupling effects among the reactor-core, steam generator, pressurizer, turbinegovernor, and different piping and plenum are most often ignored while designing the individual controllers [1]-[27]. The dynamics of actuators and sensors are also frequently omitted. Pragmatically, it is meaningful to develop control methods for the whole NPP system. However, there are very few results for controlling an entire NPP [31], [32]. In this regard, the proposed work designs state feedback control techniques using estimated states for the integrated NPP model. Both proposed techniques are applied to different subsystems of the PWR-type NPP. In particular, the paper addresses the following problems: reactor power and temperature controls, steam generator pressure control, pressurizer pressure and level controls, and turbine speed control. The efficacy of the proposed work has been tested using simulations in the MATLAB/Simulink environment. The proposed techniques have been further compared with other classical techniques. The main contributions of the paper are listed below:

- Robust-optimal hybrid control techniques are proposed to improve system performance and robustness with minimum control efforts in the presence of disturbances.

- Design, validation, and testing of the control technique is performed for various control loops of a PWR-type NPP.

- Reactor power and temperature controls, steam generator pressure control, pressurizer pressure and level controls, and turbine speed control problems are studied.

The reminder of the paper is organized as follows: Section II presents the dynamic non-linear model of a PWR-type NPP. Section III formulates the control design problem. Section IV presents the proposed control scheme. Section V implements the proposed technique on the PWR-type NPP model and discusses its effectiveness through simulation results. Conclusions are drawn in section VI indicating main contributions.

\section{Dynamic Model of a PWR Nuclear Power Plant}

The key variables of the model equations given below are described near their first occurrence, while the constant model parameters are all described, along with their units, in the nomenclature section. Typical parameter values are given in Table A.1.

\section{A. Reactor Core Model}

The core-neutronics model consisting of normalized power $\left(P_{n}\right)$ and precursor concentration of six group of delayed neutrons $\left(C_{i n}\right)$ is given by,

$$
\begin{aligned}
\frac{d P_{n}}{d t} & =\frac{\rho_{t}-\sum_{i=1}^{6} \beta_{i}}{\Lambda} P_{n}+\sum_{i=1}^{6} \frac{\beta_{i}}{\Lambda} C_{i n}, \\
\frac{d C_{i n}}{d t} & =\lambda_{i} P_{n}-\lambda_{i} C_{i n}, \quad i=1,2, \ldots 6 .
\end{aligned}
$$

The neutronic power in a reactor can be monitored using excore detectors, placed outside the core, and their associated amplifiers. The ex-core detector current $\left(i_{l o}\right)$ [33] is sensed as

$$
\tau_{1} \tau_{2} \frac{d^{2} i_{l o}}{d t^{2}}+\left(\tau_{1}+\tau_{2}\right) \frac{d i_{l o}}{d t}+i_{l o}=K_{l o} \log _{10}\left(\kappa_{l o} P_{n}\right) .
$$

The total reactivity $\left(\rho_{t}\right)$ consists of reactivity due to rod movement $\left(\rho_{\text {rod }}\right)$, and feedbacks due to variations in fuel and coolant temperatures and primary coolant pressure as

$$
\rho_{t}=\rho_{\text {rod }}+\alpha_{f} T_{f}+\alpha_{c} T_{c 1}+\alpha_{c} T_{c 2}+\alpha_{p} p_{p},
$$

where

$$
\frac{d \rho_{\text {rod }}}{d t}=G z_{\text {rod }}
$$

\section{B. Thermal-Hydraulics Model}

The thermal-hydraulics model is governed by the Mann's model which relates the core power to the temperature drop from fuel $\left(T_{f}\right)$ to coolant nodes $\left(T_{c 1}\right.$ and $\left.T_{c 2}\right)$,

$$
\begin{aligned}
\frac{d T_{f}}{d t} & =H_{f} P_{n}-\frac{1}{\tau_{f}}\left(T_{f}-T_{c 1}\right) \\
\frac{d T_{c 1}}{d t} & =H_{c} P_{n}+\frac{1}{\tau_{c}}\left(T_{f}-T_{c 1}\right)-\frac{2}{\tau_{r}}\left(T_{c 1}-T_{c i n}\right) \\
\frac{d T_{c 2}}{d t} & =H_{c} P_{n}+\frac{1}{\tau_{c}}\left(T_{f}-T_{c 1}\right)-\frac{2}{\tau_{r}}\left(T_{c 2}-T_{c 1}\right) .
\end{aligned}
$$

Resistance temperature detectors (RTDs) are used to sense the coolant temperature and its transmitter at the inlet $\left(T_{r t d 1}\right)$ and outlet $\left(T_{r t d 2}\right)$. The dynamics of these sensed temperatures can be described by [33]:

$$
\begin{gathered}
\frac{d T_{r t d 1}}{d t}=\frac{1}{\tau_{r t d}}\left(-T_{r t d 1}+2 T_{c 1}-T_{r x i}\right) \\
\frac{d T_{r t d 2}}{d t}=\frac{1}{\tau_{r t d}}\left(-T_{r t d 2}+2 T_{c 2}-T_{r x u}\right)
\end{gathered}
$$

A current signal $\left(i_{r t d}\right)$ can be obtained from the sensed RTD signals as

$$
i_{r t d}=K_{r t d} \frac{\left(\left(\left(T_{r t d 1}+T_{r t d 2}\right) / 2\right)-T_{r x i 0}\right)}{\left(T_{r x u 0}-T_{r x i 0}\right)}+4
$$




\section{Piping \& Plenum Model}

Hot-leg $\left(T_{h o t}\right)$ and cold-leg $\left(T_{\text {cold }}\right)$ pipings, reactor lower $\left(T_{r x i}\right)$ and upper $\left(T_{r x u}\right)$ plenums, steam generator inlet $\left(T_{s g i}\right)$ and outlet $\left(T_{s g u}\right)$ plenums can be represented by first order ordinary differential equations as [34],

$$
\begin{aligned}
\frac{d T_{r x u}}{d t} & =\frac{1}{\tau_{r x u}}\left(T_{c 2}-T_{r x u}\right), \\
\frac{d T_{h o t}}{d t} & =\frac{1}{\tau_{h o t}}\left(T_{r x u}-T_{h o t}\right), \\
\frac{d T_{s g i}}{d t} & =\frac{1}{\tau_{s g i}}\left(T_{h o t}-T_{s g i}\right), \\
\frac{d T_{s g u}}{d t} & =\frac{1}{\tau_{s g u}}\left(T_{p 2}-T_{s g u}\right), \\
\frac{d T_{\text {cold }}}{d t} & =\frac{1}{\tau_{c o l d}}\left(T_{s g u}-T_{c o l d}\right), \\
\frac{d T_{r x i}}{d t} & =\frac{1}{\tau_{r x i}}\left(T_{\text {cold }}-T_{r x i}\right) .
\end{aligned}
$$

\section{Steam Generator Model}

A U-tube type SG can be represented by five nodes in which, the primary coolant lump (PCL) $\left(T_{p 1}\right.$ and $\left.T_{p 2}\right)$ and metal tube lump (MTL) $\left(T_{m 1}\right.$ and $\left.T_{m 2}\right)$ are represented by two nodes each [35],

$$
\begin{aligned}
\frac{d T_{p 1}}{d t} & =\frac{1}{\tau_{p 1}}\left(T_{s g i}-T_{p 1}\right)-\frac{1}{\tau_{p m 1}}\left(T_{p 1}-T_{m 1}\right) \\
\frac{d T_{p 2}}{d t} & =\frac{1}{\tau_{p 2}}\left(T_{p 1}-T_{p 2}\right)-\frac{1}{\tau_{p m 2}}\left(T_{p 2}-T_{m 2}\right) \\
\frac{d T_{m 1}}{d t} & =\frac{1}{\tau_{m p 1}}\left(T_{p 1}-T_{m 1}\right)-\frac{1}{\tau_{m s 1}}\left(T_{m 1}-T_{s}\right) \\
\frac{d T_{m 2}}{d t} & =\frac{1}{\tau_{m p 2}}\left(T_{p 2}-T_{m 2}\right)-\frac{1}{\tau_{m s 2}}\left(T_{m 2}-T_{s}\right) .
\end{aligned}
$$

The secondary coolant lump (SCL) represent steam pressure $\left(p_{s}\right)$ by balancing mass, volume, and heat as,

$$
\begin{aligned}
\frac{d p_{s}}{d t}= & \frac{1}{K_{s}}\left[U_{m s 1} S_{m s 1}\left(T_{m 1}-T_{s}\right)+U_{m s 2} S_{m s 2}\left(T_{m 2}-T_{s}\right)\right. \\
& \left.-\left(\dot{m}_{s o} h_{s s}-\dot{m}_{f w} c_{p f w} T_{f w}\right)\right] .
\end{aligned}
$$

where,

$$
K_{s}=m_{w s} \frac{\partial h_{w s}}{\partial p_{s}}+m_{s s} \frac{\partial h_{s s}}{\partial p_{s}}-m_{w s}\left(\frac{h_{w s}-h_{s s}}{\nu_{w s}-\nu_{s s}}\right) \frac{\partial \nu_{s s}}{\partial p_{s}}
$$

\section{E. Pressurizer Model}

The water level $\left(l_{w}\right)$ in the pressurizer can be obtained by applying mass balance equation on water and steam phase as,

$$
\begin{aligned}
\frac{d l_{w}}{d t}= & \frac{1}{d_{s} A_{p}}\left(A_{p}\left(l-l_{w}\right) K_{2 p}-\frac{C_{2 p}}{C_{1 p}}\right) \frac{d p_{p}}{d t} \\
& +\frac{1}{C_{p 1}^{2}}\left(C_{2 p} \frac{d p_{p}}{d t}-\dot{m}_{\text {sur }}-\dot{m}_{s p r}\right)+\frac{\dot{m}_{\text {sur }}}{C_{1 p}}
\end{aligned}
$$

The pressure $\left(p_{p}\right)$ can be obtained by applying volume and energy balances of water and steam mixture with steam compressibility as [36],

$$
\begin{gathered}
Q_{\text {heat }}+\dot{m}_{\text {sur }}\left(\frac{p_{p} \nu_{s}}{J_{p} C_{1 p}}+\frac{h_{\bar{w}}}{C_{1 p}}\right)+ \\
\frac{d p_{p}}{d t}=\frac{\dot{m}_{s p r}\left(h_{s p r}-h_{w}+\frac{h_{\bar{w}}}{C_{1 p}}+\frac{p_{p} \nu_{w}}{J_{p} C_{1 p}}\right)}{m_{w}\left(K_{3 p}+\frac{K_{4 p} p_{p}}{J_{p}}\right)+\frac{m_{s} K_{4 p} p_{p}}{J_{p}}-} \\
\frac{V_{w}}{J_{p}}+\frac{C_{2 p}}{C_{1 p}}\left(h_{\bar{w}}+\frac{p_{p} \nu_{s}}{J_{p}}\right)
\end{gathered}
$$

where the intermediate variables are defined as,

$$
\begin{aligned}
C_{1 p} & =\frac{d_{w}}{d_{s}}-1 \\
C_{2 p} & =A_{p}\left(l-l_{w}\right) \frac{d_{w}}{d_{s}} K_{2 p}+A_{p} l_{w} K_{1 p} \\
K_{1 p} & =\frac{\partial d_{w}}{\partial p_{p}} ; K_{2 p}=\frac{\partial d_{s}}{\partial p_{p}} ; K_{3 p}=\frac{\partial h_{w}}{\partial p_{p}} ; K_{4 p}=\frac{\partial \nu_{s}}{\partial p_{p}} .
\end{aligned}
$$

The surge rate $\left(\dot{m}_{\text {sur }}\right)$ can be represented using coolant temperatures at different nodes as

$$
\dot{m}_{\text {sur }}=\sum_{j=1}^{N} V_{j} \vartheta_{j} \frac{d T_{j}}{d t}
$$

\section{F. Turbine Model}

The dynamical model of a turbine consisting of the highpressure, intermediate-pressure, and low-pressure turbines is given by [37],

$$
\begin{array}{r}
\frac{d^{2} P_{h p}}{d t}+\left(\frac{O_{r v}+\tau_{i p}}{\tau_{h p} \tau_{i p}}\right) \frac{d P_{h p}}{d t}+\left(\frac{O_{r v}}{\tau_{h p} \tau_{i p}}\right) P_{h p}=\left(\frac{O_{r v} F_{h p}}{\tau_{h p} \tau_{i p}}\right) \overline{\dot{m}}_{s o} \\
+\left(\frac{\left(1+\kappa_{h p}\right) F_{h p}}{\tau_{h p}}\right) \frac{d \bar{m}_{s o}}{d t} \\
\frac{d^{2} P_{i p}}{d t}+\left(\frac{O_{r v} \tau_{h p}+\tau_{i p}}{\tau_{h p} \tau_{i p}}\right) \frac{d P_{i p}}{d t}+\left(\frac{O_{r v}}{\tau_{h p} \tau_{i p}}\right) P_{i p}=\left(\frac{O_{r v} F_{i p}}{\tau_{h p} \tau_{i p}}\right) \overline{\dot{m}}_{s o} \\
\frac{d^{3} P_{l p}}{d t}+\left(\frac{O_{r v} \tau_{h p}+\tau_{i p}}{\tau_{h p} \tau_{i p}}+\frac{1}{\tau_{l p}}\right) \frac{d^{2} P_{l p}}{d t}+\left(\frac{O_{r v}\left(\tau_{l p}+\tau_{h p}\right)+\tau_{i p}}{\tau_{h p} \tau_{i p} \tau_{l p}}\right) \\
\frac{d P_{l p}}{d t}+\left(\frac{O_{r v}}{\tau_{h p} \tau_{i p} \tau_{l p}}\right) P_{l p}=O_{r v} F_{l p} \overline{\dot{m}}_{s o}
\end{array}
$$

where the steam flow is $\overline{\dot{m}}_{s o}=\dot{m}_{s o} / \dot{m}_{\text {sor }}, \dot{m}_{s o r}$ is the rated steam mass flow rate. The steam flow rate can be modified using the turbine-governor control valve coefficient $\left(C_{t g}\right)$ as

$$
\begin{gathered}
\dot{m}_{s o}=C_{t g} p_{s} \\
\frac{d^{2} C_{t g}}{d t^{2}}+2 \zeta_{t g} \omega_{t g} \frac{d C_{t g}}{d t}+\omega_{t g}^{2} C_{t g}=\omega_{t g}^{2} K_{t g} u_{t g}
\end{gathered}
$$

where $u_{t g}$ is the input signal to the valve. The total mechanical output of turbine $\left(P_{\text {tur }}\right)$ is computed as,

$$
P_{t u r}=P_{h p}+P_{i p}+P_{l p} .
$$

where $P_{h p}, P_{i p}$, and $P_{l p}$ are mechanical power outputs of high-pressure, intermediate-pressure, low-pressure turbine, respectively.

The turbine-generator model also consists of a turbine speed system which produces the rate of change in turbine speed $\left(z_{\text {tur }}\right)$ in accordance with the difference in generator demand power $\left(P_{d e m}\right)$ and turbine output as

$$
\frac{d z_{t u r}}{d t}=\frac{P_{t u r}-P_{d e m}}{(2 \pi)^{2} J_{t u r} z_{t u r} I_{t g}} .
$$




\section{PROBLEM Formulation}

Consider a linear time invariant system given by

$$
\begin{aligned}
& \dot{x}(t)=A x(t)+B u(t)+B \xi(t)+\omega(t) \\
& y(t)=C x(t)+v(t)
\end{aligned}
$$

where $x(t) \in \mathbb{R}^{n}, u(t) \in \mathbb{R}^{m}, y(t) \in \mathbb{R}^{l}$, and $\xi(t) \in \mathbb{R}^{m}$ respectively represent state vector, control input, system output, and uncertainty. $\omega(t)$ and $v(t)$ are process noise and measurement noise with zero mean and covariance matrices $E\left(\omega(t) \omega(t)^{\top}\right)=\Xi$ and $E\left(v(t) v(t)^{\top}\right)=\Theta$, respectively. $A \in \mathbb{R}^{n \times n}, B \in \mathbb{R}^{n \times m}$, and $C \in \mathbb{R}^{l \times n}$ are system matrices. It is assumed that $(A, B)$ is controllable and that the system uncertainties are unknown and bounded, so that

$$
\|\xi(t)\| \leq \xi^{*}, \quad \xi^{*}>0 .
$$

The control aim is to force the system output $y(t)$ to follow the desired reference $r(t)$ with minimal control effort in the presence of uncertainty $\xi(t)$. To achieve this objective the control scheme, depicted in Fig. 1, is proposed in this work, where the robust control reduces the effect of uncertainties and the optimal control guarantees minimum control effort. The control law $u(t)$ is formed of two parts, i.e.,

$$
u(t)=u_{n}(t)+u_{d}(t)
$$

where the nominal control $\left(u_{n}(t)\right)$ is produced using LQG to obtain nominal system performance in an optimal way whereas the discontinuous control $\left(u_{d}(t)\right)$ is generated by ISM to compensate for uncertainties. Thus, (35) can be written as

$$
\begin{aligned}
\dot{x}(t) & =A x(t)+B\left(u_{n}(t)+u_{d}(t)+\xi(t)\right)+\omega(t) \\
y(t) & =C x(t)+v(t)
\end{aligned}
$$

\section{Proposed Hybrid Control Design Scheme}

\section{A. Nominal Control Design}

The nominal control uses the LQG approach, which involves two steps, state estimation using a Kalman filter and optimal state feedback control using the LQT.

1) Kalman Filter: The Kalman filter estimation problem is to find an optimal state estimate $\hat{x}(t)$ such that the following error covariance is minimized:

$$
J_{1}=\lim _{t \rightarrow \infty} E\left\{(x-\hat{x})(x-\hat{x})^{\top}\right\}
$$

The Kalman filtering problem is estimated by computing the Kalman gain $K_{f}$ given by

$$
K_{f}=P_{f} C^{\top} \Theta^{-1}
$$

where $P_{f}$ is a symmetric positive semidefinite matrix and can be computed using a solution of following Algebraic Riccati Equation (ARE) as

$$
A P_{f}+P_{f} A^{\top}+\Gamma \Xi \Gamma^{\top}-P_{f} C^{\top} \Theta^{-1} C P_{f}=0
$$

where $\Gamma \in \mathbb{R}^{n \times m}$ is disturbance input matrix. Thus, the estimated states $\hat{x}(t)$ for the nominal system are given by,

$$
\dot{\hat{x}}(t)=A \hat{x}(t)+B u(t)+K_{f}(y(t)-C \hat{x}(t)) .
$$

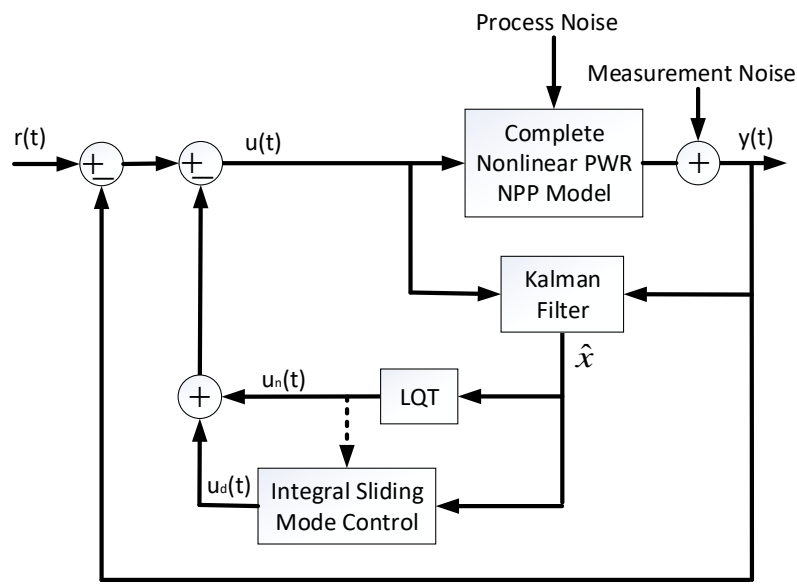

Fig. 1: Block diagram representation of the proposed hybrid control strategy.

2) Linear Quadratic Tracker: The classical linear quadratic regulator design is modified to track the reference signal. The LQT design computes an optimal control input by minimizing the cost function [38]:

$$
J_{2}=\int_{0}^{\infty}\left((C \hat{x}-r)^{\top} Q(C \hat{x}-r)+u_{n}^{\top} R u_{n}\right) d \tau
$$

where $Q$ and $R$ are positive semidefinite and positive definite weighing matrices, respectively. Thus, the state feedback control law is given by,

$$
u_{n}(t)=-K_{c} \hat{x}(t)+K_{v} s(t)
$$

where the optimal feedback gain $K_{c}$ is computed by finding a solution of the following ARE

$$
A^{\top} P_{c}+P_{c} A+C^{\top} Q C-P_{c} B R^{-1} B^{\top} P_{c}=0
$$

It is given by

$$
K_{c}=R^{-1} B^{\top} P_{c}
$$

where $P_{c}$ is a symmetric positive semidefinite matrix. The feed-forward gain $K_{v}$ is computed as

$$
K_{v}=R^{-1} B
$$

and $s(t)$ is given by the solution of

$$
-\dot{s}(t)=\left(A-B K_{c}\right)^{\top} s(t)+C^{\top} Q r(t), s(\infty)=0
$$

Thus, the optimal state feedback nominal control law is then implemented using the estimated states as

$$
u_{n}(t)=-R^{-1} B^{\top} P_{c} \hat{x}(t)+R^{-1} B^{\top} s(t)
$$

\section{B. Loop Transfer Recovery}

Due to the incorporation of a Kalman filter for state estimation, the robustness and stability margin of the nominal control are weakened [39]. To resolve this, either the gain of Kalman filter or the gain of tracker can be modified using the 
LTR approach. The gains are shaped so that the resultant filter transfer function has guaranteed stability margins. The openloop system with the LQG return ratio at the input is given by

$$
G(s)=K_{c}\left(s I-A+B K_{c}+K_{f} C\right)^{-1} K_{f} C(s I-A)^{-1} B
$$

The LTR at the input can be designed as follows: First, the LQT is designed by suitably selecting $Q$ and $R$. Then, $\Gamma=B$, $\Xi=q \Xi$ and $\Theta=I$ are selected. The idea of LTR design is to use a fictitious gain coefficient $q$ and then gradually increase $q \rightarrow \infty$, such that the final loop-transfer function approximates to the state-feedback loop transfer function designed by the LQT as

$$
\lim _{q \rightarrow \infty} G(s)=K_{c}(s I-A)^{-1} B
$$

The proposed LQG/LTR-ISM scheme first designs the nominal control using LQG and enhances the stability using the LTR technique and then combines with the ISM approach. Thus, the hybrid approach possess strong robustness capability with enhanced performance.

\section{Discontinuous Control Design}

The ISM works by designing first an integral sliding manifold followed by the design of a discontinuous control law. The sliding motion occurs on the integral sliding manifold whereas the control law drives the system trajectories onto the sliding manifold and maintained on it. An integral sliding manifold $\phi(t) \in \mathbb{R}^{m}=\left[\phi_{1}(t) \phi_{2}(t) \cdots \phi_{m}(t)\right]^{\top}$ can be designed as [28],

$$
\phi(t)=G\left[\hat{x}(t)-\hat{x}(0)-\int_{0}^{\top} \dot{\hat{x}}_{n}(\tau) d \tau\right]
$$

where $G \in \mathbb{R}^{m \times n}$ is the design freedom. For simplicity, it is selected as left-pseudo inverse of input distribution matrix $B$ given as

$$
G=\left(B^{\top} B\right)^{-1} B^{\top}
$$

The term $-\hat{x}(0)$ assures that the system starts from the sliding manifold by eliminating the reaching phase and enforcing $\phi(0)=0$. Thus, the closed-loop system turns out to be robust towards matched uncertainties from the initial time instant. Here, the discontinuous control $u_{d}(t)$ is formulated based on the reachability condition [40]

$$
u_{d}(t)=-\mu \operatorname{sign}(\phi(t))
$$

where $\mu$ is an appropriately designed positive constant and $\operatorname{sign}($.$) is the standard signum function.$

\section{Stability Analysis}

A Lyapunov function $V(t)$ is selected as [41]

$$
V(t)=\frac{1}{2} \phi^{\top}(t) \phi(t)
$$

Differentiating $V(t)$ with respect to time gives

$$
\dot{V}(t)=\phi^{\top}(t) \dot{\phi}(t)=\phi^{\top}(t) G\left(\dot{\hat{x}}(t)-\dot{\hat{x}}_{n}(t)\right)
$$

During sliding mode, the system trajectories follow the nominal system trajectories i.e., $\hat{x}(t)=\hat{x}_{n}(t)$. Thus, (56) becomes

$$
\begin{aligned}
\dot{V}(t) & =\phi^{\top}(t)\left(u_{d}(t)+\xi(t)\right)=\phi^{\top}(t)(-\mu \operatorname{sign}(\phi(t))+\xi(t)) \\
& =-\mu \phi^{\top}(t) \operatorname{sign}(\phi(t))+\phi^{\top}(t) \xi(t) \\
& \leq-\mu|\phi(t)|+|\phi(t)||\xi(t)| \\
& \leq|\phi(t)|\left(-\mu+\xi^{*}\right)
\end{aligned}
$$

Thus, for any choice of $\mu \geq \xi^{*}+\delta$, (57) becomes

$$
\dot{V}(t)=\phi^{\top}(t) \dot{\phi}(t) \leq-\delta|\phi(t)|
$$

where $\delta$ is a small positive constant.

It is apparent from (58) that the trajectories of uncertain system will be maintained on the sliding manifold $\phi(t)=0$ and drive towards the specified equilibrium point despite the uncertainties in finite time. The boundary layer approach can be used to restrain the effect of chattering due to the presence of signum function [41]. The signum function can be approximated as,

$$
\operatorname{sign}\left(\phi_{i}(t)\right)=\frac{\phi_{i}(t)}{\left|\phi_{i}(t)\right|+\varepsilon} \quad i=1,2, \cdots m
$$

where $\varepsilon$ is a small positive constant. The boundary layer technique results in loss of invariance property and steady state error proportional to boundary layer thickness. Thus, for good performance the value of $\epsilon$ should be selected as small as possible [40]. A more prominent approach to reduce the effect of chattering is higher order sliding mode control.

\section{Result AND Discussion}

The simulation results test the performance of the designed controllers under various conditions. The controllers are tested on the nonlinear PWR-type NPP model under disturbances of sinusoidal and chirp nature. The following important control loops are considered: reactor power and temperature loop, temperature loop, steam generator loop, pressurizer loop, and turbine speed loop. In each case, the results of the proposed control schemes are compared with other classical state feedback techniques such as LQG and LQG/LTR schemes. The definition of input and output vector for every single-inputsingle-output control loop is given in Table I. The value of tuning parameters of the controllers for different loops is given in Table I.

\section{A. Reactor Power Loop}

The performance of the designed controllers is tested for typical load-following transients of a PWR-type NPP in the presence of disturbances. The disturbances added to the system are given by

$$
\begin{aligned}
& \omega_{1}(t)=10^{-3} \sin \left(2 \pi \times 10^{-4} t+3.96 \pi \times 10^{-6} t^{2}\right) \\
& \omega_{2}(t)=10^{-4}(\sin (0.05 t)+2 \sin (0.1 t)+3 \sin (0.15 t))(61)
\end{aligned}
$$

where the disturbance $\omega_{1}(t)$ is added to total reactivity in (4) and the disturbance $\omega_{2}(t)$ is added to the rod speed in (5). 


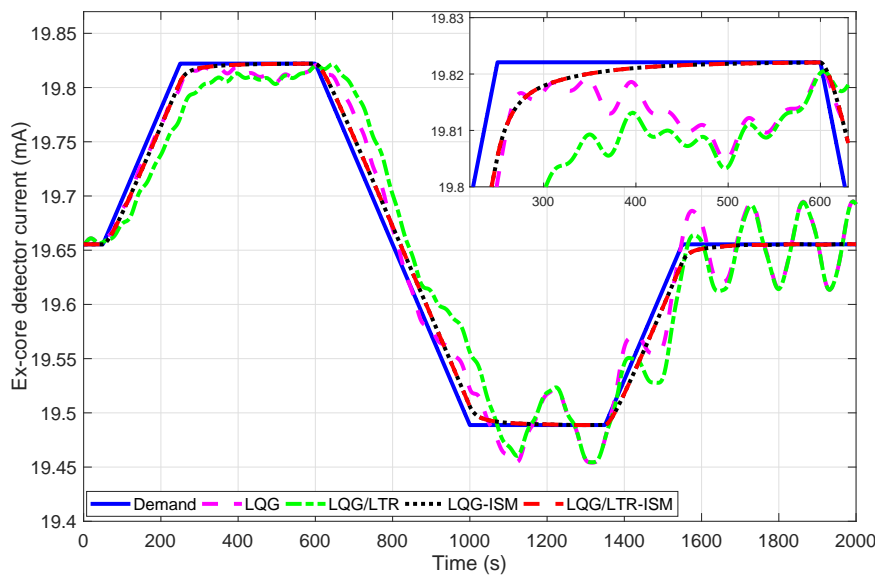

(a) Ex-core detector current.

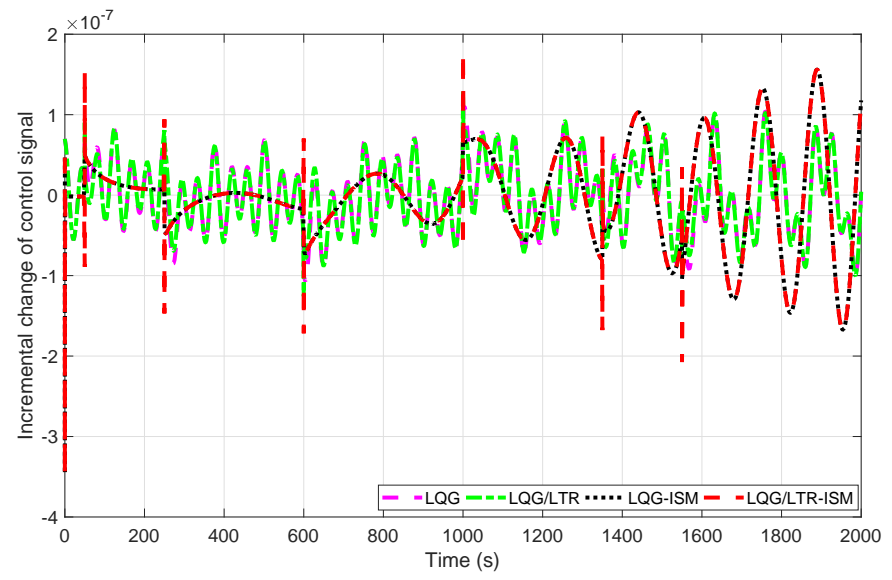

(c) Incremental change of control rod speed.

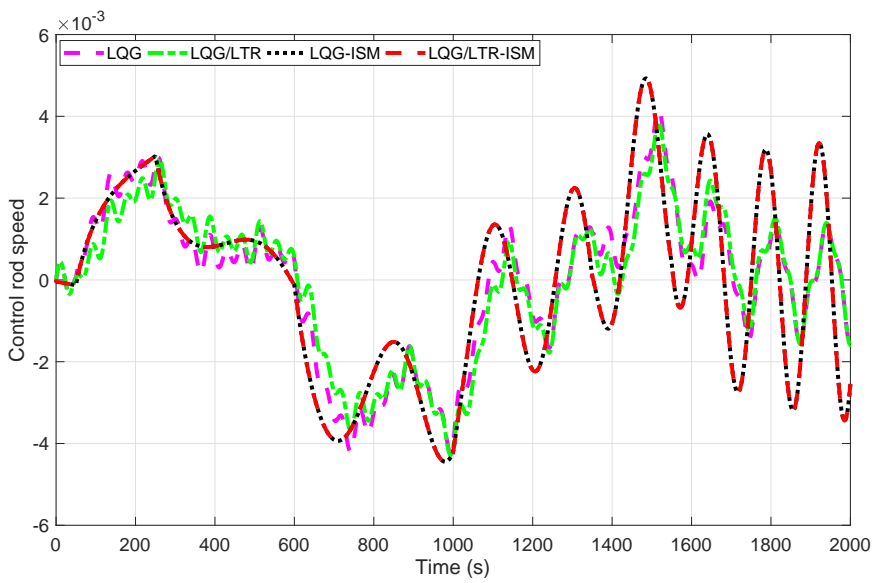

(b) Control rod speed.

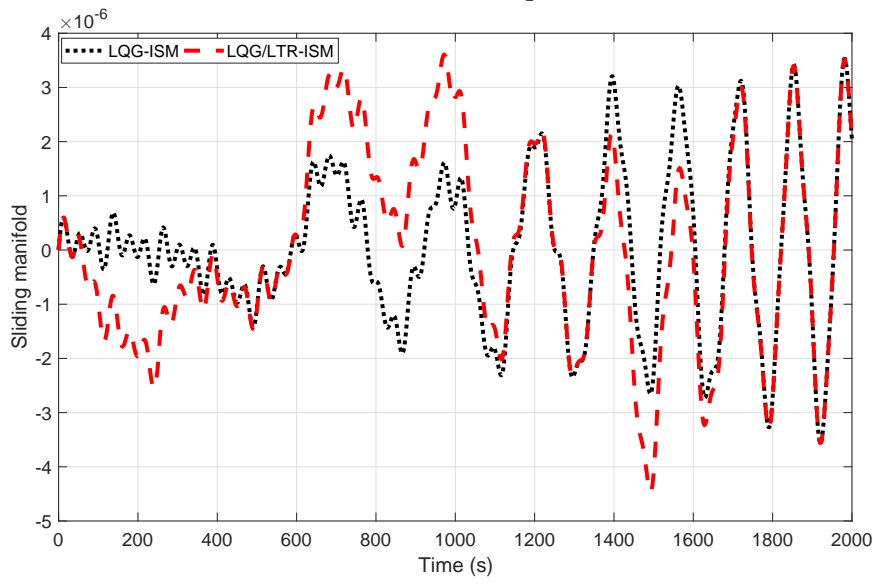

(d) Sliding manifold.

Fig. 2: Variation of reactor power signals during load-following mode of operation.

1) Case I: Initially, the NPP is assumed to be operating at $100 \%$ full power (FP). A load-following transient is considered to study typical power variations in which the reference power is varied at $6.6 \% / \mathrm{min}$ in a ramp manner. It is given as follows:

$$
P_{n}^{r e f}=\left\{\begin{array}{lc}
1, & 0 \leq t \leq 50 \\
0.0011(t-50)+1, & 50<t \leq 250 \\
1.22, & 250<t \leq 600 \\
-0.0011(t-700)+1.22, & 600<t \leq 1000(62) \\
0.78, & 1000<t \leq 1350 \\
0.0011(t-1900)+0.78, & 1350<t \leq 1550 \\
1, & 1550<t \leq 2000
\end{array}\right.
$$

The performance of the controllers, in terms of measured excore detector current corresponding to output power is shown in Fig. 2a. The variations of control signal and its incremental change are shown in Figs. $2 \mathrm{~b}$ and $2 \mathrm{c}$, respectively. The design of sliding manifolds using LQG-ISM and LQG/LTR-ISM is shown in Fig. 2d. It can be noticed that the LQG and LQG/LTR controllers are unable to reject the disturbances whereas the LQG-ISM and LQG/LTR-ISM controllers can track the variations smoothly as envisaged. The LQG-ISM and LQG/LTR-ISM schemes take similar control efforts which are lower than that taken by the LQG and LQG/LTR techniques.
2) Case II: Another load-following transient is considered to validate the performance during an emergency operation. The reference power value is brought down from $100 \%$ to $20 \%$ FP in a step manner and then it is slowly brought back to its initial steady-state value power at $5 \% / \mathrm{min}$ ramp. The transient is given as follows:

$$
P_{n}^{r e f}= \begin{cases}1.0, & 0 \leq t \leq 50 \\ 0.2, & 50<t \leq 500 \\ 0.05(t-500) / 60+0.2, & 500<t \leq 1460 \\ 1.0, & 1460<t \leq 2000\end{cases}
$$

The performance of the controllers in terms of measured excore detector current are shown in Fig. 3a. The variations of control signal and its incremental change are shown in Figs. $3 \mathrm{~b}$ and $3 \mathrm{c}$, respectively. The design of sliding manifolds using LQG-ISM and LQG/LTR-ISM is shown in Fig. 3d. The LQG/LTR controller gives better performance than the LQG controller where the latter gives large overshoot however, both of them are unable to handle the disturbances. The LQG-ISM and LQG/LTR-ISM are able to track the sudden $80 \%$ load rejection transient without any overshoot and are able to reject the disturbances present in the system. The LQG-ISM and LQG/LTR-ISM are found to give better control performance over the LQG and LQG/LTR approaches. 


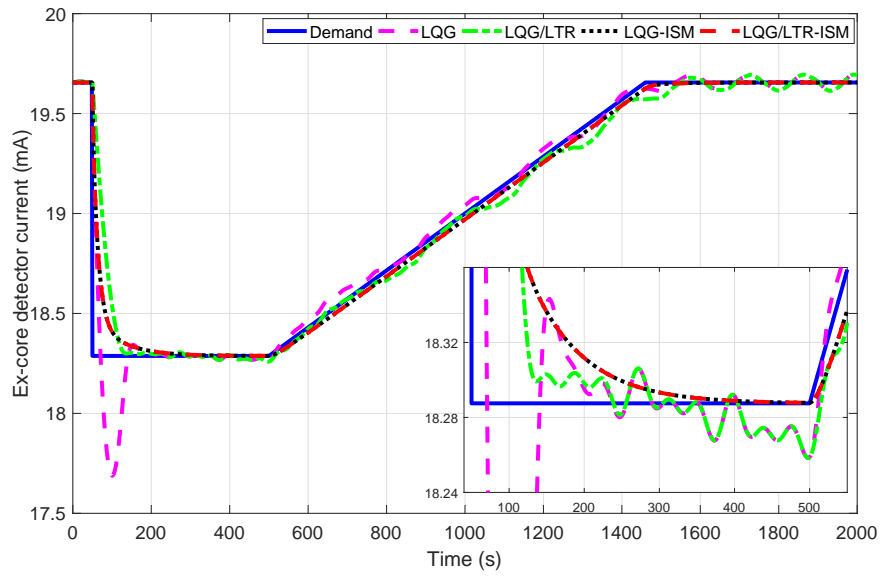

(a) Ex-core detector current.

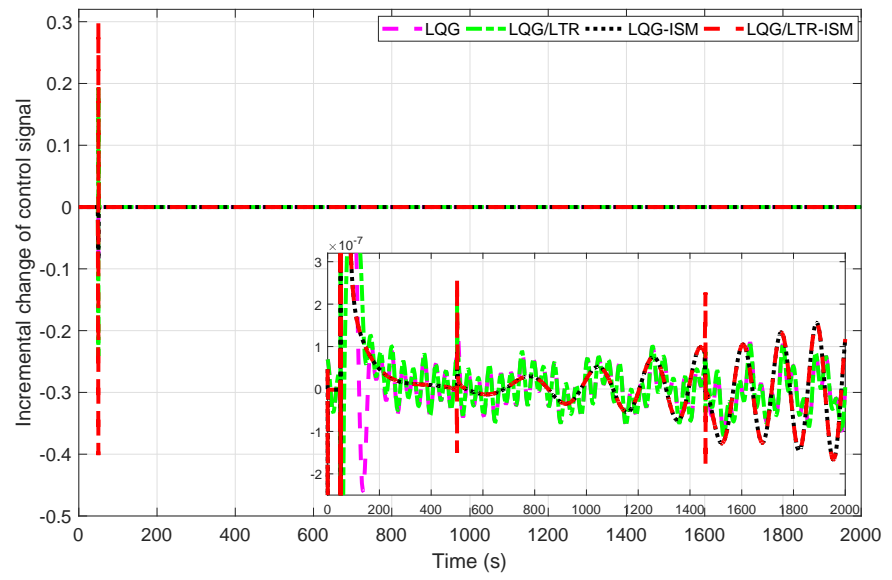

(c) Incremental change of control rod speed.

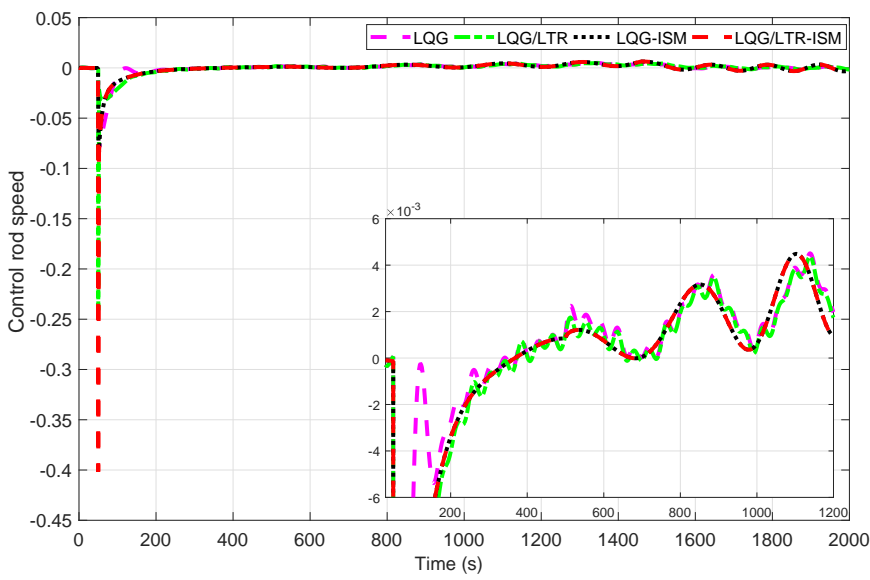

(b) Control rod speed.

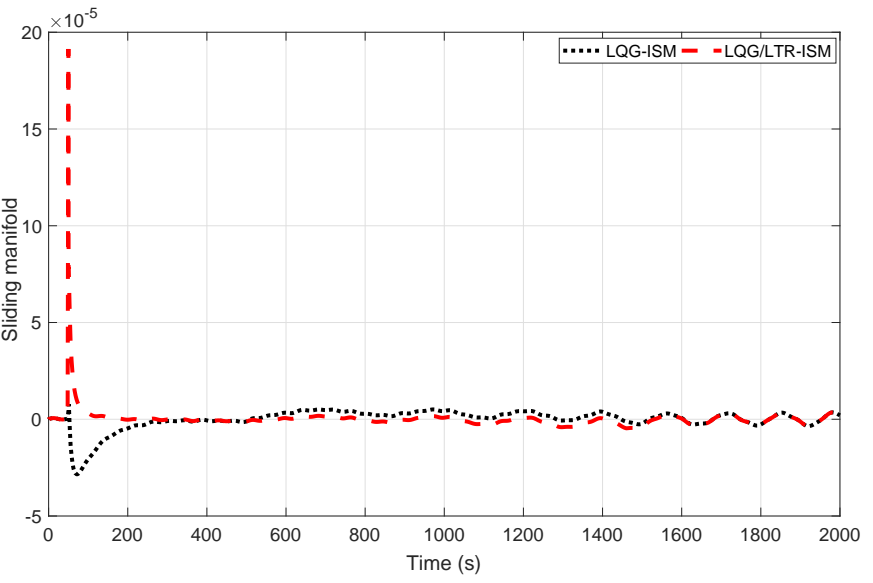

(d) Sliding manifold.

Fig. 3: Variation of reactor power signals during load-following mode of operation.

\section{B. Temperature Control Loop}

The NPP power can also be controlled using the coolant temperature. To analyse the performance of temperature control, in the presence of disturbances similar to V-A, a loadfollowing transient is considered as follows:

$$
P_{n}^{r e f}=\left\{\begin{array}{lc}
1, & 0 \leq t \leq 50 \\
-0.001(t-50)+1, & 50<t \leq 250 \\
0.80, & 250<t \leq 700 \\
0.001(t-700)+0.80, & 700<t \leq 900 \\
1, & 900<t \leq 1250(64) \\
0.001(t-1250)+1, & 1250<t \leq 1450 \\
1.20, & 1450<t \leq 1900 \\
-0.001(t-1900)+1.20, & 1900<t \leq 2100 \\
1, & 2100<t \leq 2500
\end{array}\right.
$$

The performance of the controllers, in terms of measured RTD current corresponding to the output power is shown in Fig. 4a. The variations of control signal and its incremental change are shown in Figs. $4 \mathrm{~b}$ and $4 \mathrm{c}$, respectively. The design of sliding manifolds using LQG-ISM and LQG/LTR-ISM is shown in Fig. 4d. The LQG-ISM and LQG/LTR-ISM controllers can track the variation smoothly in the presence disturbances however, the LQG and LQG/LTR controllers are unable to do so. The LQG-ISM and LQG/LTR-ISM approaches take lower control efforts than the other approaches.

\section{Steam Generator Loop}

The performance of the designed controllers is tested for a set-point change in steam generator pressure in the presence of disturbances. The disturbances added to the system are given by

$$
\begin{aligned}
& \omega_{1}(t)=10^{-3} \sin \left(2 \pi \times 10^{-4} t+1.98 \pi \times 10^{-5} t^{2}\right) \\
& \omega_{2}(t)=10^{-2}(\sin (0.1 t)+2 \sin (0.2 t)+5 \sin (0.5 t))
\end{aligned}
$$

where the disturbance $\omega_{1}(t)$ is added to the valve coefficient in (31) and the disturbance $\omega_{2}(t)$ is added to the input signal to the turbine governor valve in (32). A set-point change in the secondary pressure is applied as follows:

$$
p_{s}^{r e f}=\left\{\begin{array}{lc}
7.285, & 0 \leq t \leq 100 \\
10^{-3}(t-100)+7.285, & 100<t \leq 150 \\
7.335, & 150<t \leq 300 \\
-10^{-3}(t-300)+7.335, & 300<t \leq 350 \\
7.285, & 350<t \leq 500
\end{array}\right.
$$

The performance of the controllers is shown in Fig. 5a. The variation of control signal and its incremental change are shown in Figs. 5b and 5c, respectively. The design of sliding 


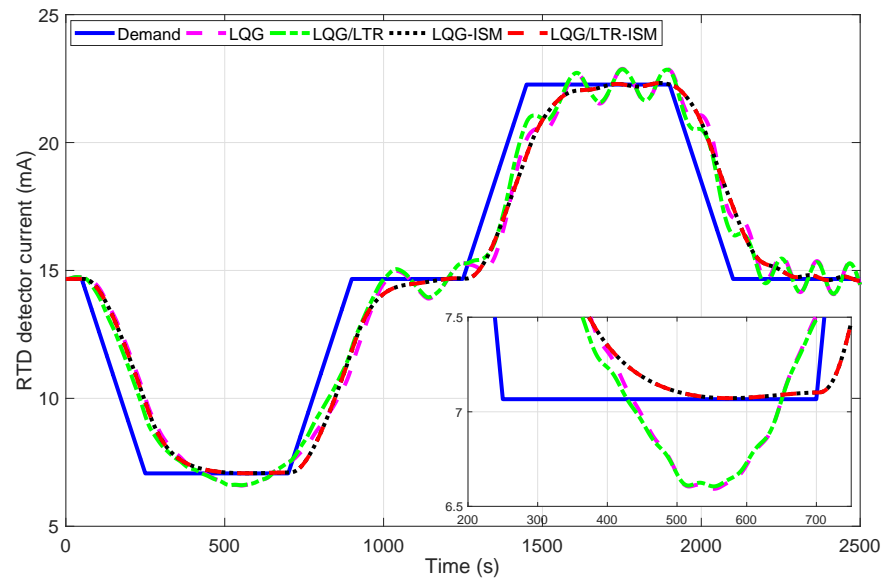

(a) RTD current.

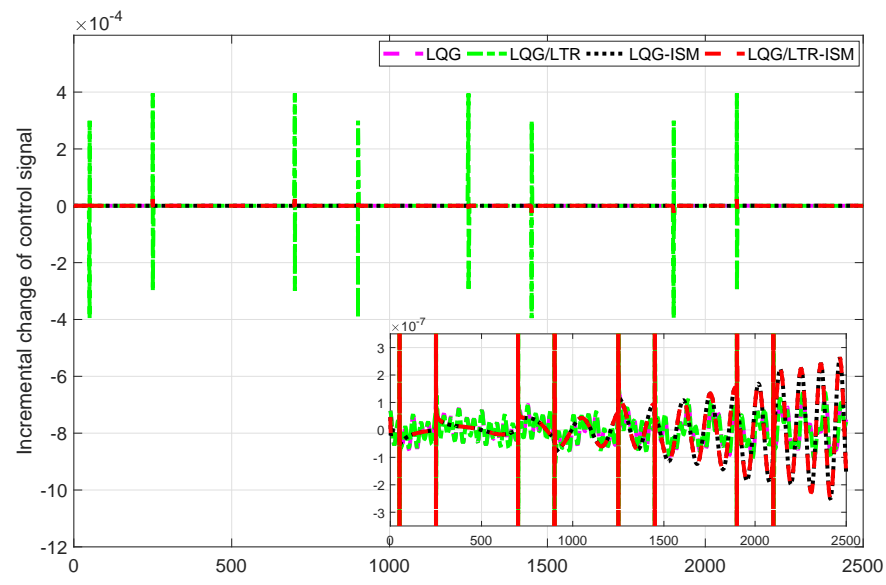

(c) Incremental change of control rod speed.

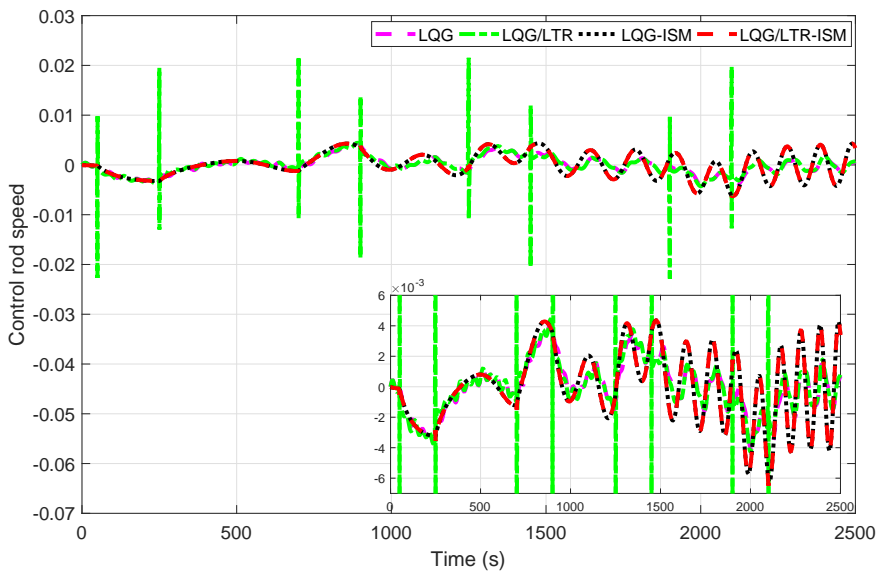

(b) Control rod speed movement.

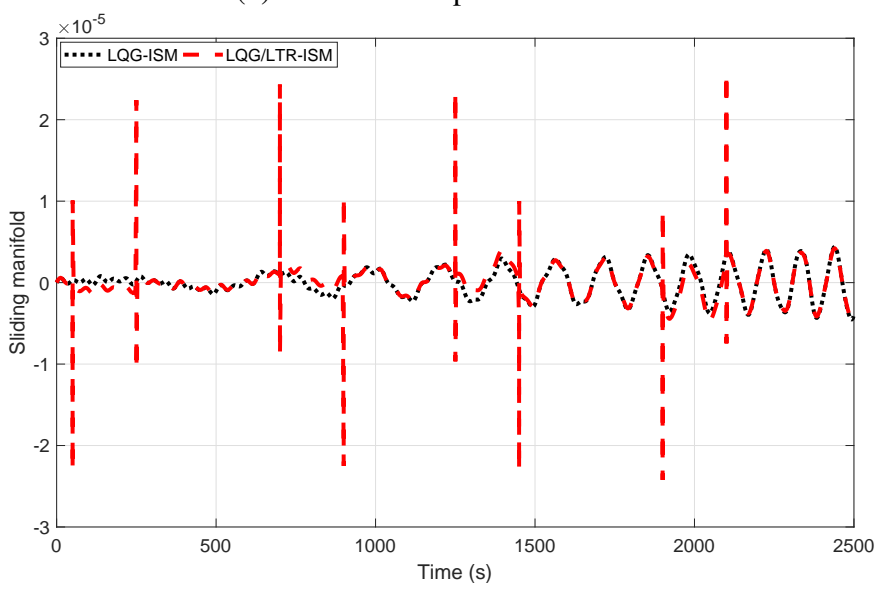

(d) Sliding manifold.

Fig. 4: Variation of reactor temperature signals during load-following mode of operation.

manifolds using LQG-ISM and LQG/LTR-ISM is shown in Fig. 5d. It can be observed that the LQG-ISM and LQG/LTRISM are able to track the variation smoothly in the presence of disturbances. On the contrary, the LQG and LQG/LTR controllers are unable to reject the disturbances. The control efforts taken by LQG-ISM and LQG/LTR-ISM are found to be significantly lower than that of the other approaches.

\section{Pressurizer Loop}

The pressurizer pressure control is usually achieved by actuating bank of heaters and by adjusting the spray flow rate. The performance of the designed controllers is tested for a set-point change in pressurizer pressure in the presence of disturbances. The disturbances added to the system are given by

$$
\begin{aligned}
& \omega_{1}(t)=0.2 \sin (0.1 t)+0.4 \sin (0.2 t)+\sin (0.5 t) \\
& \omega_{2}(t)=10^{-2} \sin \left(2 \pi \times 10^{-4} t+1.998 \pi \times 10^{-4} t^{2}\right)
\end{aligned}
$$

where the disturbances $\omega_{1}(t)$ and $\omega_{2}(t)$ are added to the input signal and to the surge flow in (25), respectively.
1) Pressure Control by Heater: A set-point change in the pressurizer pressure is applied as follows:

$$
p_{p}^{r e f}= \begin{cases}15.41, & 0 \leq t \leq 50 \\ 10^{-4}(t-50)+15.41, & 50<t \leq 100 \\ 15.415, & 100<t \leq 200\end{cases}
$$

The increment in reference pressure actuates the heater system. The performance of the controllers is shown in Fig. 6a. It can be observed that the all the controllers able to track the set-point however, the LQG and LQG/LTR controllers are unable to reject the disturbances whereas the LQG-ISM and LQG/LTR-ISM are able to effectively handle the disturbances. The variation of control signal and its incremental change are shown in Figs. $6 \mathrm{~b}$ and $6 \mathrm{c}$, respectively. The design of sliding manifolds using LQG-ISM and LQG/LTR-ISM is shown in Fig. 6d. All the control schemes are found to take similar control efforts out of which the LQG-ISM and LQG/LTR-ISM takes the minimum efforts.

2) Pressure Control by Spray: A set-point change in the pressurizer pressure is applied as follows:

$$
p_{p}^{r e f}=\left\{\begin{array}{lc}
15.41, & 0 \leq t \leq 50 \\
-10^{-4}(t-100)+15.41, & 50<t \leq 100 \\
15.405, & 100<t \leq 200
\end{array}\right.
$$




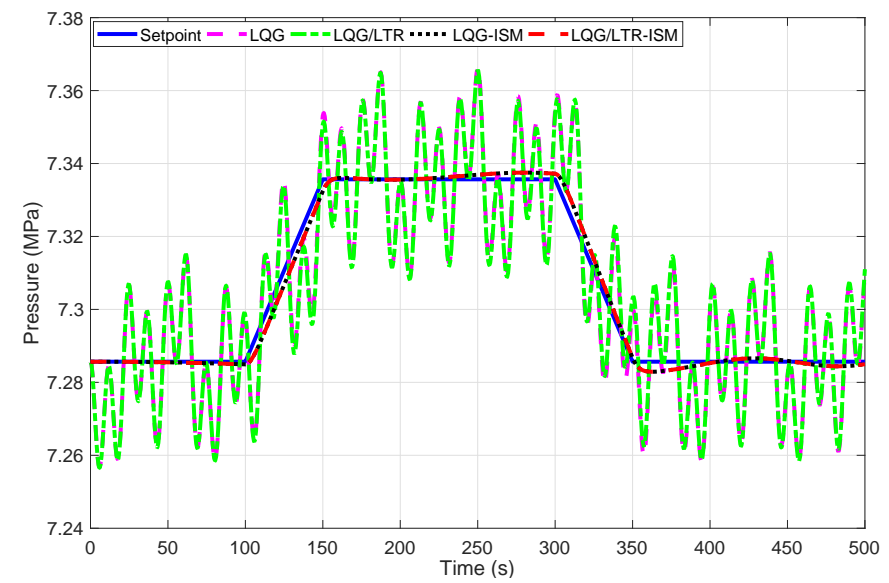

(a) Steam generator secondary pressure.

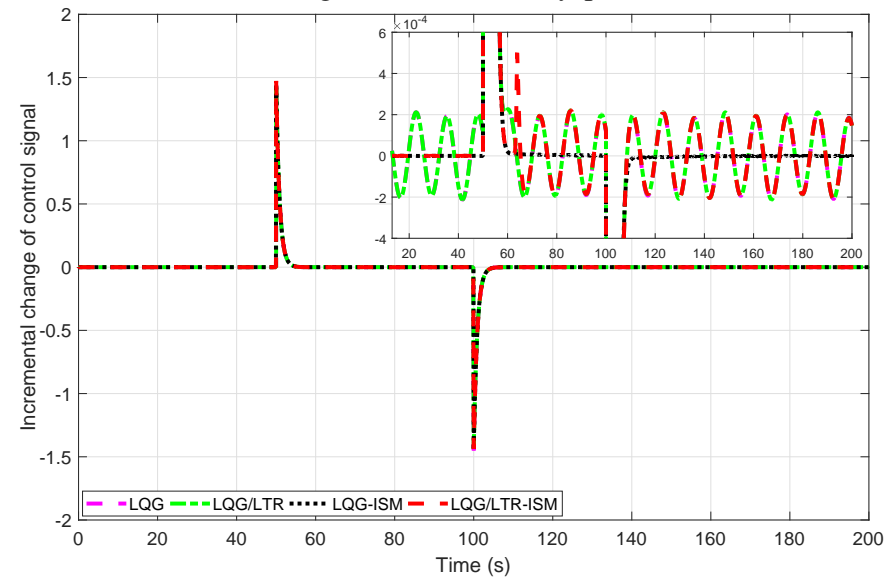

(c) Incremental change of control signal.

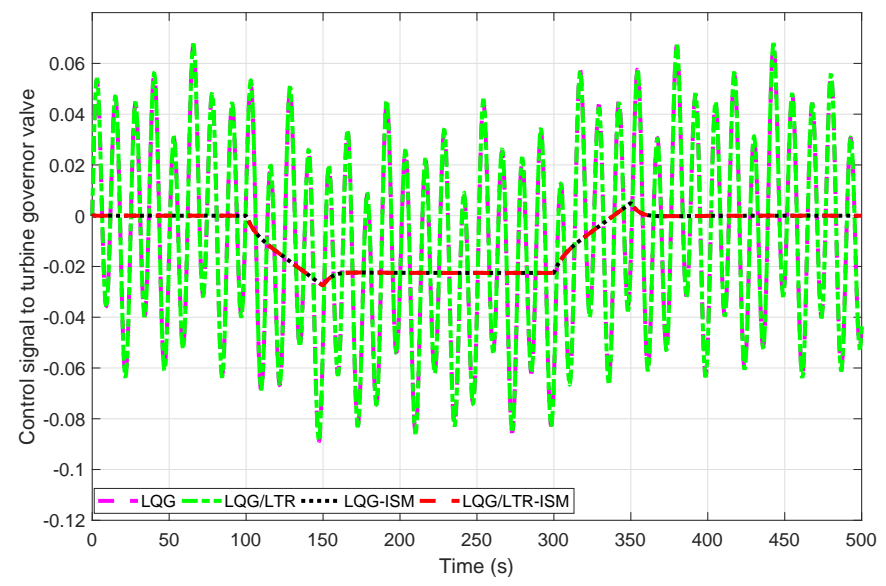

(b) Control signal to turbine governor valve.

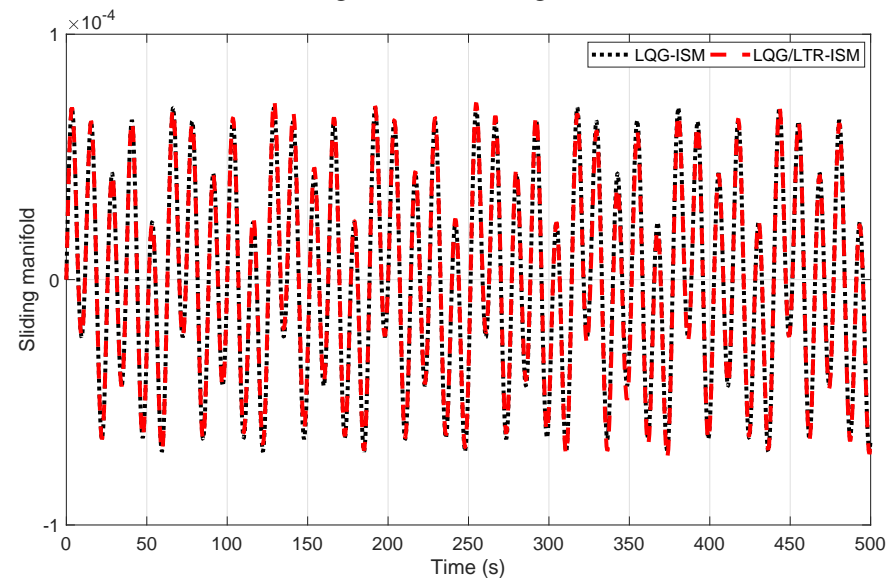

(d) Sliding manifold.

Fig. 5: Variation of steam generator during a set-point change in secondary pressure.

The decrement in reference pressure actuates the spray flow system. The performance of the proposed controller is shown in Fig. 7a. It can be observed that LQG and LQG/LTR controllers are able to track the set-point with superimposed disturbances. The LQG-ISM and LQG/LTR-ISM are able to reject the disturbances and smoothly track the set-point variation. The variation of control signal and its incremental change are shown in Figs. 7b and 7c, respectively. The design of sliding manifolds using LQG-ISM and LQG/LTR-ISM is shown in Fig. 7d. The control efforts taken by LQG-ISM and LQG/LTR-ISM are found to be lower than that of the other approaches.

3) Level Control: The pressurizer level control system maintains the water level for the reactor core coolant system. A set-point change in the level is applied as follows:

$$
l_{w}^{r e f}=\left\{\begin{array}{lc}
28.06, & 0 \leq t \leq 50 \\
-0.01(t-50)+28.06, & 50<t \leq 100 \\
27.56, & 100<t \leq 250 \\
0.01(t-250)+27.56, & 250<t \leq 300 \\
28.06, & 300<t \leq 400
\end{array}\right.
$$

The performance of the controllers is shown in Fig. 8a. The LQG-ISM and LQG/LTR-ISM are able to track the set-point variation smoothly in the presence of disturbances whereas the LQG and LQG/LTR controllers are unable to reject the disturbances. The control signal variation and the incremental change of control signal are shown in Figs. 8b and 8c, respectively. The design of sliding manifolds using LQG-ISM and LQG/LTR-ISM is shown in Fig. 8d. The LQG-ISM and LQG/LTR-ISM are found to spend lower control energies than that of the other approaches.

\section{E. Turbine Speed Loop}

The turbine speed control system regulates the shaft speed by controlling the steam flow to the turbine through the turbine governor valve. The performance of the proposed technique is tested in regulating the demand power using turbine speed in the presence of disturbances. The disturbances added to the system are given by

$$
\begin{aligned}
& \omega_{1}(t)=10^{-3} \sin \left(2 \pi \times 10^{-4} t+1.998 \pi \times 10^{-4} t^{2}\right) \\
& \omega_{2}(t)=0.2 \sin (0.1 t)+0.4 \sin (0.2 t)+\sin (0.5 t)
\end{aligned}
$$

where $\omega_{1}(t)$ is added to valve coefficient in (31) and $\omega_{2}(t)$ is added to the input signal to the turbine governor valve in (32). 


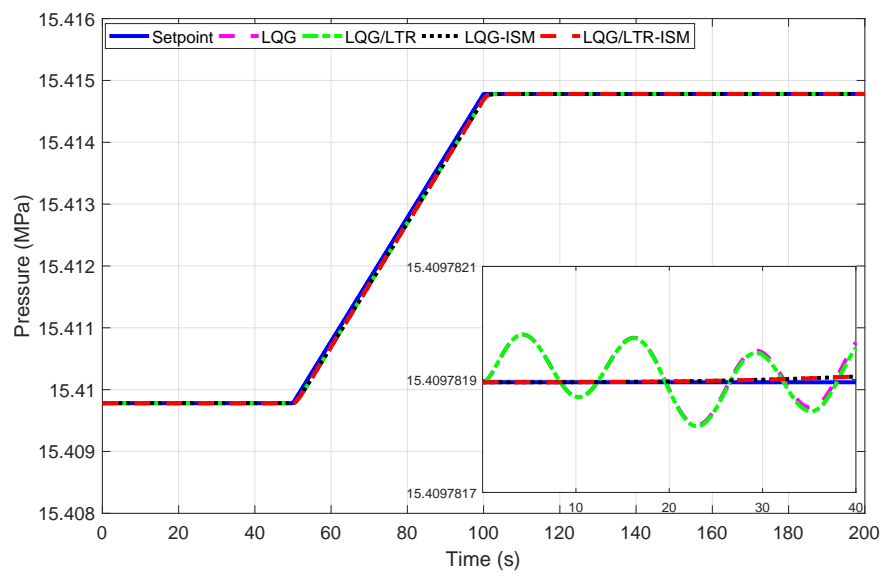

(a) Pressurizer pressure.

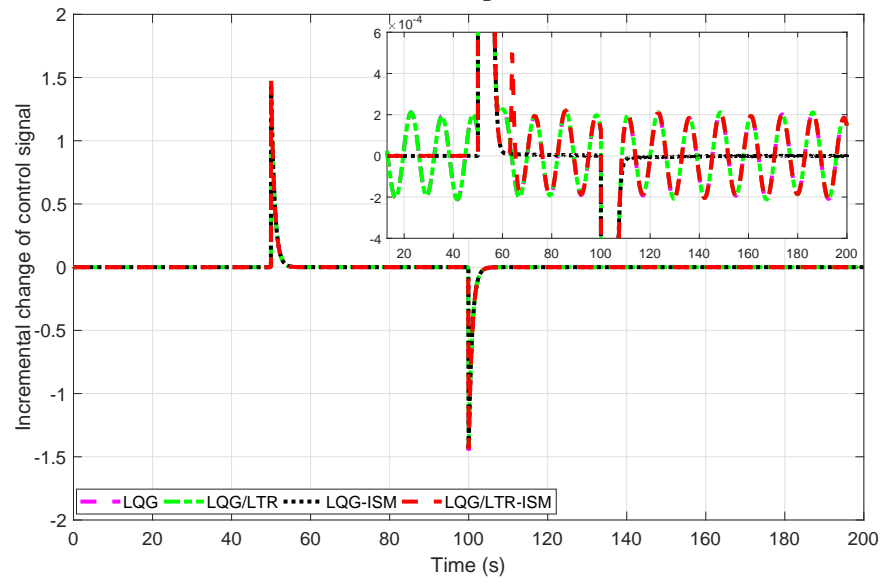

(c) Incremental change of control signal.

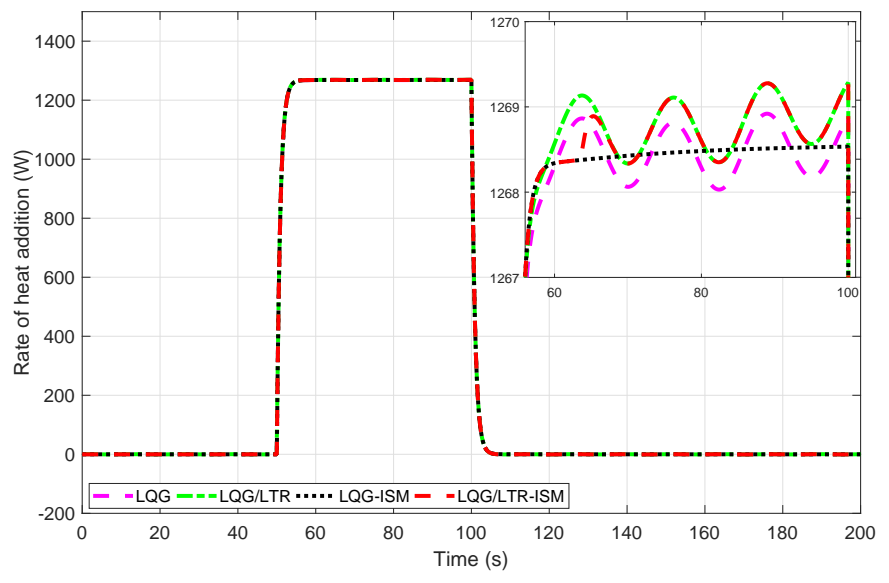

(b) Rate of heat addition.

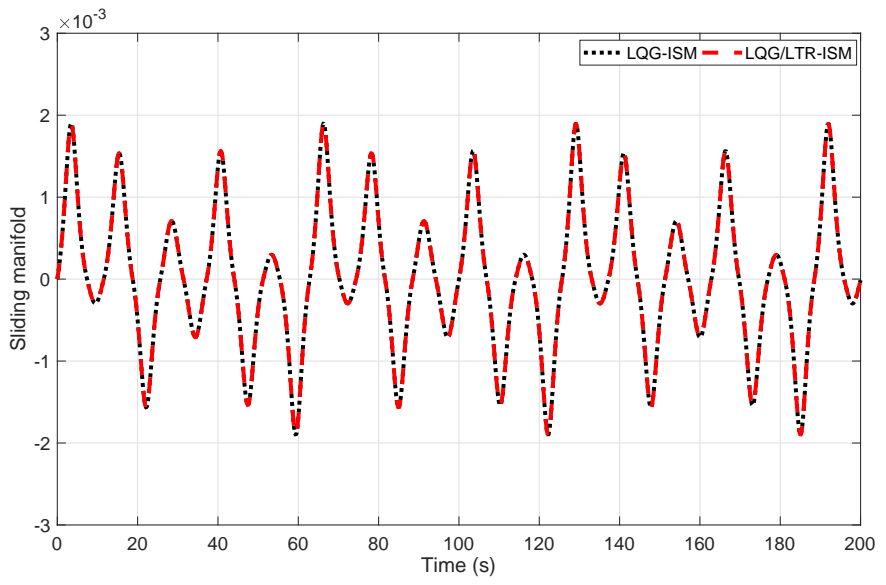

(d) Sliding manifold.

Fig. 6: Variation of pressurizer heater signals during set-point change in pressure.

The demand power from the generator is changed as follows:

$$
P_{\text {dem }}^{r e f}=\left\{\begin{array}{lc}
1, & 0 \leq t \leq 50 \\
0.002(t-50)+1, & 50<t \leq 100 \\
0.90, & 100<t \leq 1500
\end{array}\right.
$$

The performance of the proposed controllers for tracking the set-point change in demand power is shown in Fig. 9a. The LQG and LQG/LTR controllers track the variation with disturbances superimposed. The LQG-ISM and LQG/LTRISM are able to track the set-point variation smoothly in the presence of disturbances. The control signal variation and the incremental change of control signal are shown in Figs. 9b and $9 \mathrm{c}$, respectively. The design of sliding manifolds using LQGISM and LQG/LTR-ISM is shown in Fig. 9d. The LQG-ISM and LQG/LTR-ISM are found to spend lower control energies than that of the other approaches.

\section{F. Performance Assessment}

The performance of different controllers is dependent on the tuning parameters. In the case of LQG, the $Q$ and $R$ matrices regulate the penalties on the states variables and control input, respectively. If $Q$ is a diagonal matrix, large diagonal elements results in the poles of the closed-loop system far from the origin and the state tracks the reference rapidly. On the contrary, if $R$ is a diagonal matrix, large diagonal elements results in the poles of the closed-loop system close to the origin and the state tracks the reference slowly. Thus, the values of $Q$ and $R$ are tuned such that the set-point can be tracked quickly without any overshoot. In the case of LTR, the recovery gain $q$ is selected based on the frequency response of the target feedback loop. The value of $q$ is selected such that the loop transfer function approaches the ideal return ratio given by the target feedback loop. The tuning parameter of ISM is selected to ensure that the discontinuous control signal does not contain high-freuqnecy noise. The values of different tuning parameters adopted during simulations for each scheme are given in Table I.

The control performance can be statistically analysed based on the following measures. Firstly, the percentage root mean squared error (PRMSE) is calculated on the basis of tracking error. Secondly, the effect of control action on input is analysed by computing the total variation of input (TVI) and the $\mathcal{L}_{2}$ norm of input $\left(\mathcal{L}_{2} \mathrm{NI}\right)$. These are given by,

$$
\text { PRMSE }=\sqrt{\frac{1}{N} \sum_{i=1}^{N}\left(y_{i}-r_{i}\right)^{2}} \times 100 \%,
$$




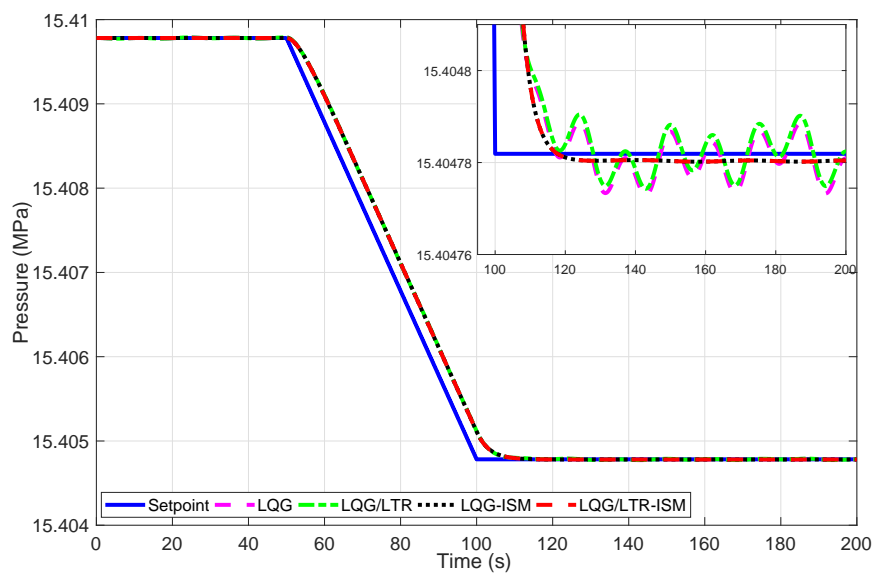

(a) Pressurizer pressure.

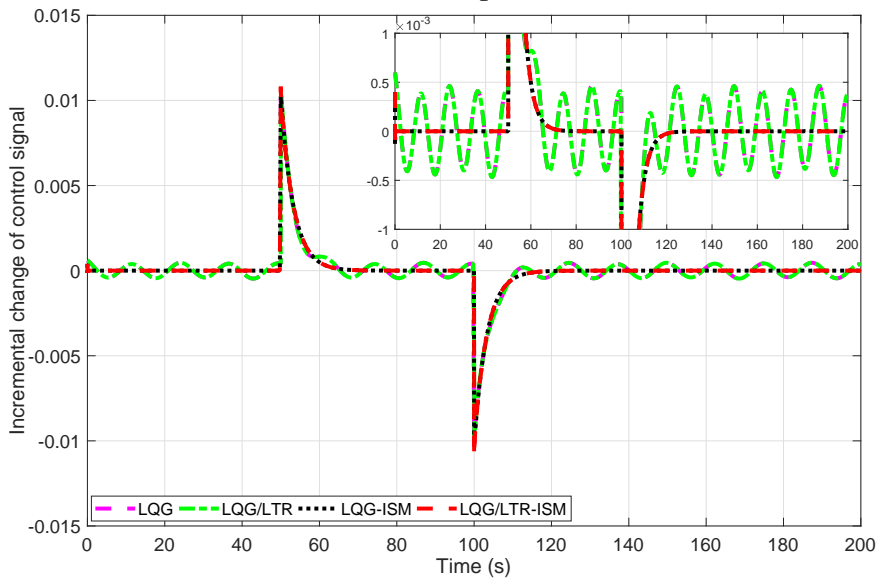

(c) Incremental change of control signal.

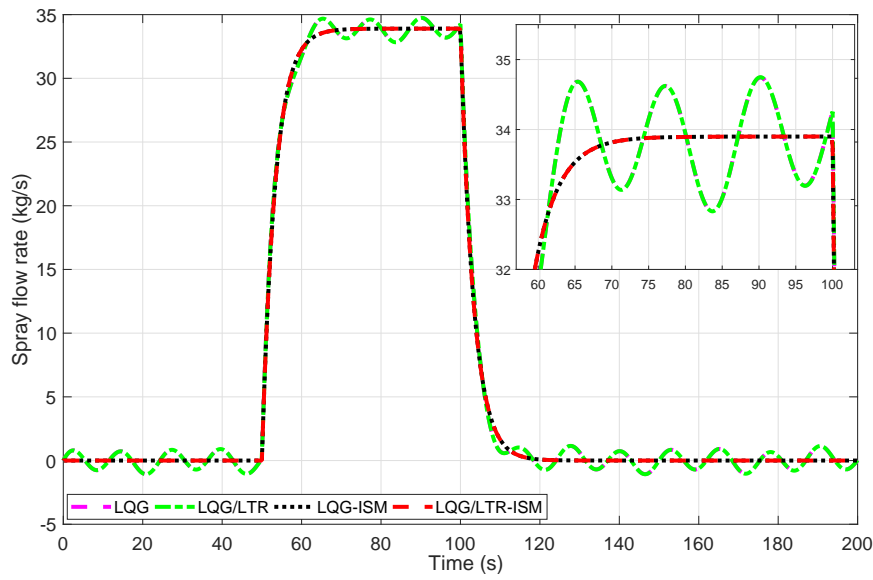

(b) Rate of spray flow.

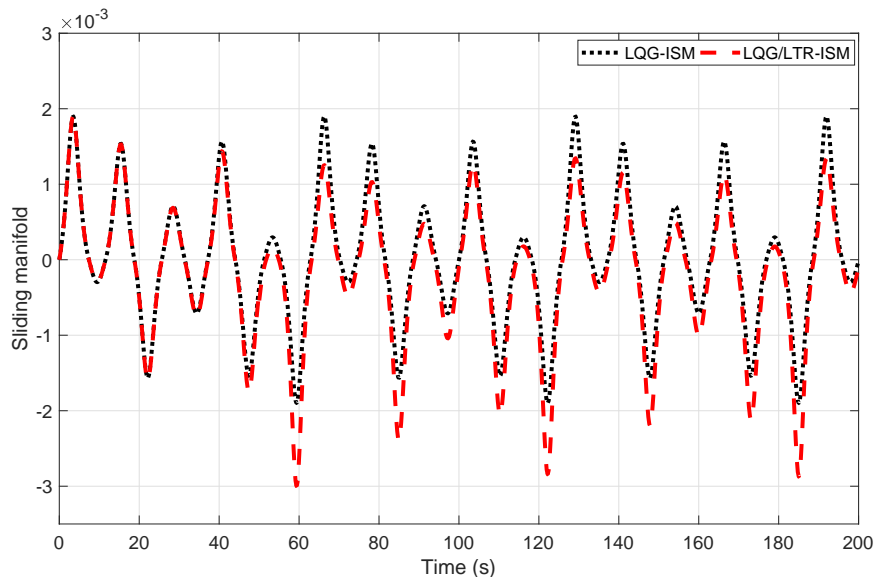

(d) Sliding manifold.

Fig. 7: Variation of pressurizer spray flow signals during set-point change in pressure.

TABLE I: Tuning parameters for different control approaches

\begin{tabular}{|c|c|c|c|c|c|c|c|c|}
\hline \multicolumn{3}{|c|}{ Configuration } & \multicolumn{4}{|c|}{ LQG } & LTR & ISM \\
\hline Case & Input & Output & $Q$ & $R$ & $\Xi$ & $\Theta$ & $q$ & $\mu$ \\
\hline A. 1 & $z_{\text {rod }}$ & $i_{l o}$ & $1 \times 10^{-3} I_{n}$ & $1 \times 10^{5}$ & $5 \times 10^{-3} I_{n}$ & 1 & $1 \times 10^{9}$ & 1 \\
\hline A. 2 & $z_{r}$ & & $1 \times 10^{-3} I_{n}$ & $1 \times 10^{5}$ & $5 \times 10^{-3} I_{n}$ & 1 & $1 \times 10^{9}$ & 1 \\
\hline B & $z_{r}$ & & $1 \times 10^{-3} I_{n}$ & $1 \times 10^{5}$ & $5 \times 10^{-4} I_{n}$ & 1 & $1 \times 10^{9}$ & 1 \\
\hline $\mathrm{C}$ & & $p_{s}$ & $5 \times 10^{-2} I_{n}$ & $1 \times 10^{2}$ & $5 \times 10^{-3} I_{n}$ & 1 & $1 \times 10^{9}$ & 1 \\
\hline D.1 & $Q_{\text {heat }}$ & $p_{p}$ & $1 \times 10^{0} I_{n}$ & $1 \times 10^{-10}$ & $5 \times 10^{-5} I_{n}$ & 1 & $1 \times 10^{20}$ & 2 \\
\hline D.2 & $\dot{m}$ & $p_{p}$ & $5 \times 10^{-3} I_{n}$ & $1 \times 10^{-8}$ & $5 \times 10^{-5} I_{n}$ & 1 & $1 \times 10^{15}$ & 2 \\
\hline D.3 & $\dot{m}_{\text {sur }}$ & $l_{w}$ & $1 \times 10^{0} I_{n}$ & $1 \times 10^{-6}$ & $5 \times 10^{-3} I_{n}$ & 1 & $1 \times 10^{12}$ & 2 \\
\hline $\mathrm{E}$ & $u_{t}$ & ur & $1 \times 10^{5} I_{n}$ & $1 \times 10^{-2}$ & $5 \times 10^{-4} I_{n}$ & 1 & $1 \times 10^{4}$ & 2 \\
\hline
\end{tabular}

$$
\begin{aligned}
T V I & =\sum_{i=1}^{N}\left|u_{i+1}-u_{i}\right|, \\
\mathcal{L}_{2} N I & =\sqrt{\sum_{i=1}^{N}\left(u_{i}\right)^{2}}
\end{aligned}
$$

where $N$ denotes the total number of samples, which is equal to simulation time divided by sampling interval where the sampling interval is taken as $1 \mathrm{~ms}$. Table II compares the control performance of LQG, LQG/LTR, LQG-ISM, and LQG/LTR-ISM approaches. It is found that the values of
PRMSE for the LQG/LTR-ISM approach is lower than those of the other approaches in all the cases. The value of TVI and the $\mathcal{L}_{2} \mathrm{NI}$ are also found to be lower for the LQG-ISM and LQG/LTR-ISM approaches. The performance of LQG/LTR is slightly better than the LQG, however both of the techniques are unable to provide the desired response in the presence of disturbances. It can be concluded that the proposed LQGISM and LQG/LTR-ISM controllers provide better set-point tracking over other control approaches with minimum control efforts. 


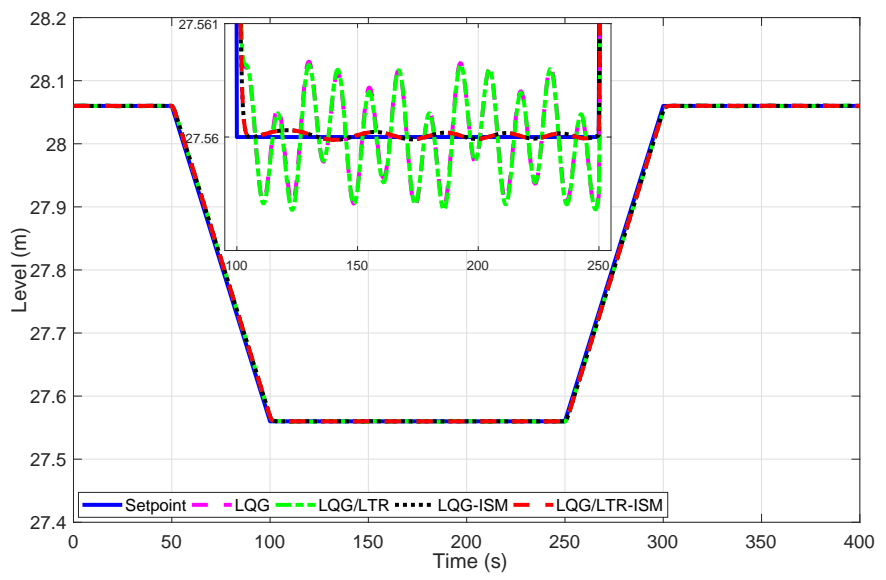

(a) Pressurizer level.

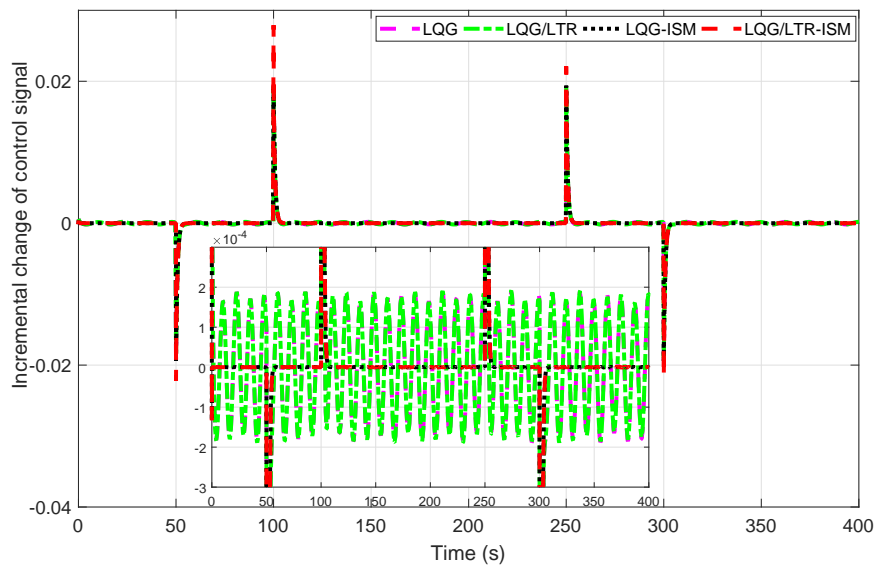

(c) Incremental change of control signal.

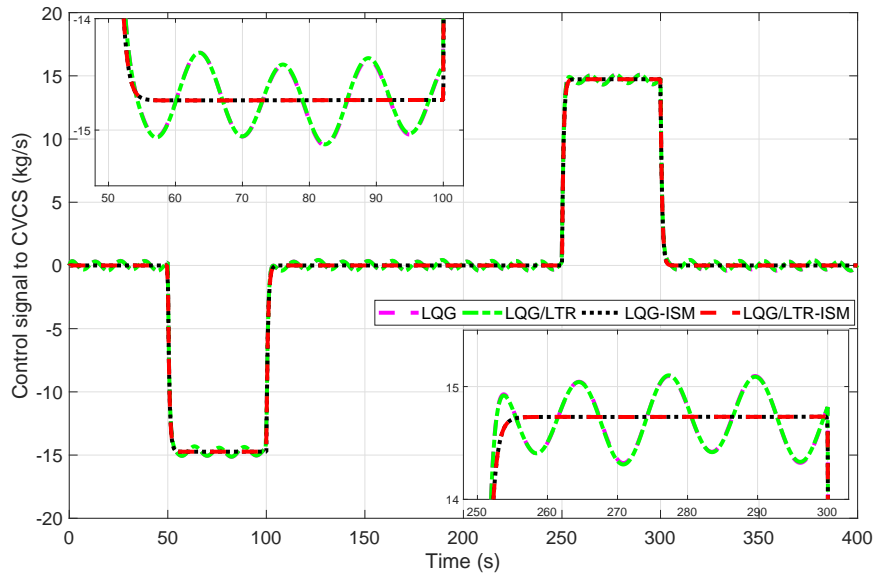

(b) Control signal to CVCS system.

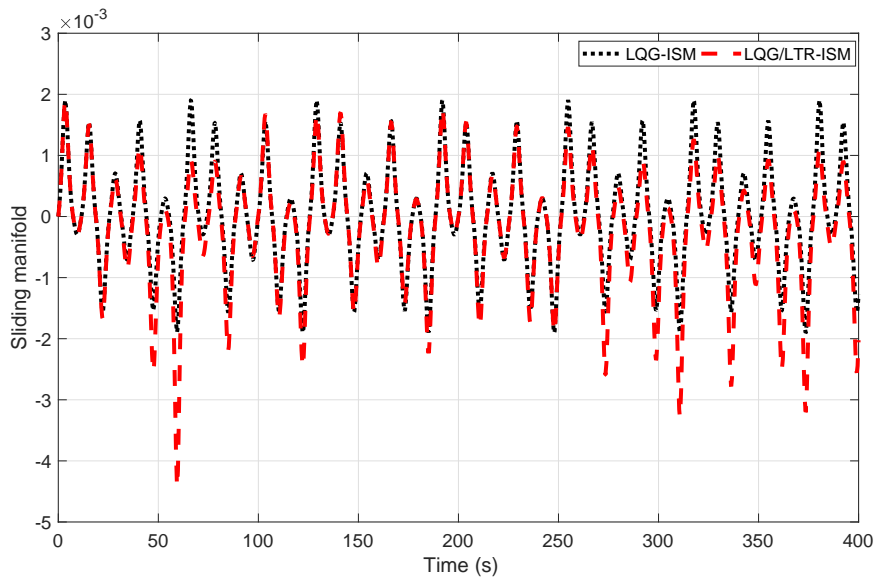

(d) Sliding manifold.

Fig. 8: Variation of pressurizer level signals during set-point change in level.

\section{Vi. CONCLUSIONS}

This work proposes state feedback-based hybrid control design techniques by integrating robust-optimal approaches for the control of a pressurized water-type nuclear power plant. The robust-optimal hybrid control technique combines the LQG-ISM approach with the loop transfer recovery technique. The control architecture thus offers enhanced robustness with improved performance and tracks the reference set-point smoothly in the presence disturbances. The effectiveness of the techniques has been validated using simulations on different subsystems of the PWR-type NPP. The control performances of the proposed approaches have been quantitatively compared with LQG and LQG/LTR control approaches using different statistical measures for reactor power and temperature controls, steam generator pressure control, pressurizer pressure and level controls, and turbine speed control. The proposed controllers can handle disturbances in the system and they have been found giving better performance over other controllers.

\section{ACKNOWLEDGEMENT}

The work presented in this paper has been financially supported under grants EP/R021961/1 and EP/R022062/1 from the Engineering and Physical Sciences Research Council.

\section{APPENDIX}

The value of different parameters used in the model are given in Table A.1 [34]-[37].

\section{NOMENCLATURE}

\begin{tabular}{|c|c|}
\hline$A_{p}$ & Cross-sectional area of pressurizer $\left(\mathrm{m}^{2}\right)$ \\
\hline$C_{i n}$ & $\begin{array}{l}\text { Normalized delayed neutron precursor concen- } \\
\text { tration (per unit) }\end{array}$ \\
\hline$C_{t g}$ & Turbine governor valve coefficient \\
\hline$G$ & Reactivity worth $(m K)$ \\
\hline$H$ & Rate of rise of temperature $\left({ }^{0} \mathrm{C} / \mathrm{J}\right)$ \\
\hline$I$ & Moment of inertia $\left(\mathrm{kg} \cdot \mathrm{m}^{2}\right)$ \\
\hline$J$ & Conversion factor \\
\hline$K$ & Gain \\
\hline$P_{n}$ & Normalized power (per unit) \\
\hline$Q_{\text {heat }}$ & Rate of heat addition $(k W)$ \\
\hline$S$ & Effective heat transfer area $\left(m^{2}\right)$ \\
\hline$T$ & Average temperature $\left({ }^{0} C\right)$ \\
\hline$U$ & Heat transfer coefficient $\left(\mathrm{W} / \mathrm{m}^{2} .{ }^{0} \mathrm{C}\right)$ \\
\hline$V$ & Volume $\left(m^{3}\right)$ \\
\hline$c_{p}$ & Specific heat $\left(J / k g .{ }^{0} C\right)$ \\
\hline$d$ & Density $\left(\mathrm{kg} / \mathrm{m}^{3}\right)$ \\
\hline$h$ & Enthalpy $(\mathrm{J} / \mathrm{kg})$ \\
\hline$i$ & Current $(m A)$ \\
\hline
\end{tabular}




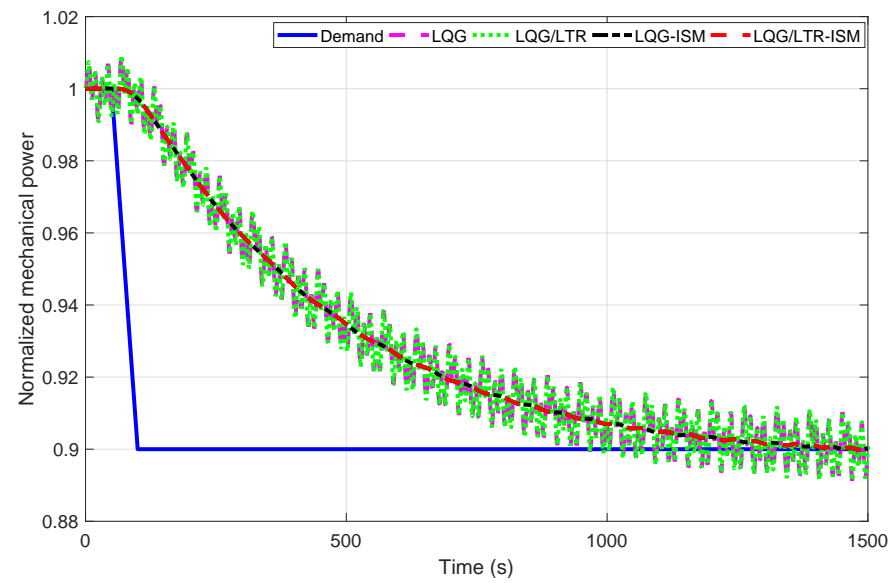

(a) Normalized mechanical power.

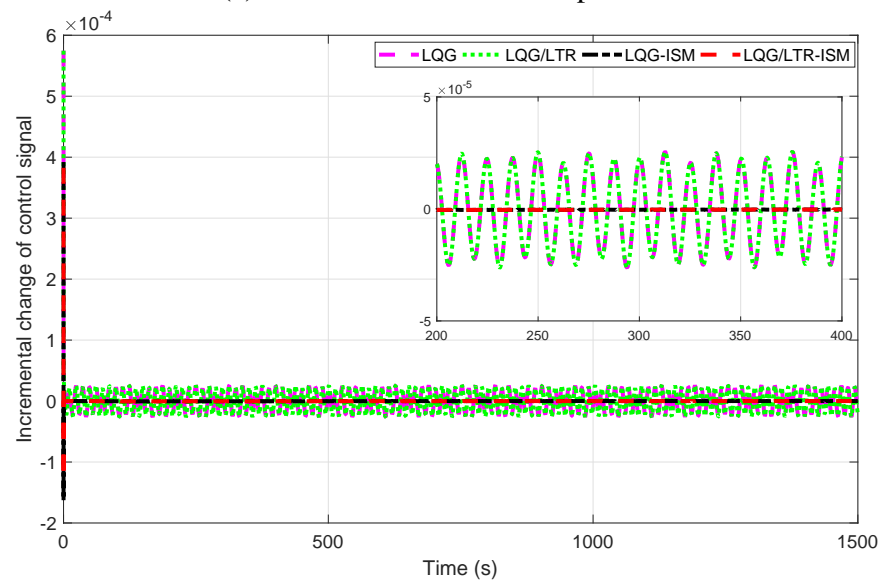

(c) Incremental change of control signal.

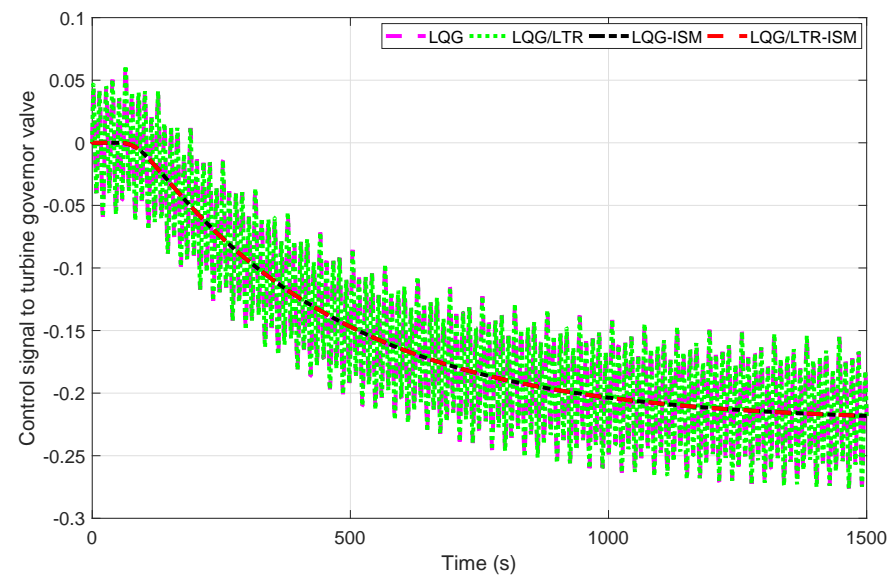

(b) Control signal to turbine governor valve.

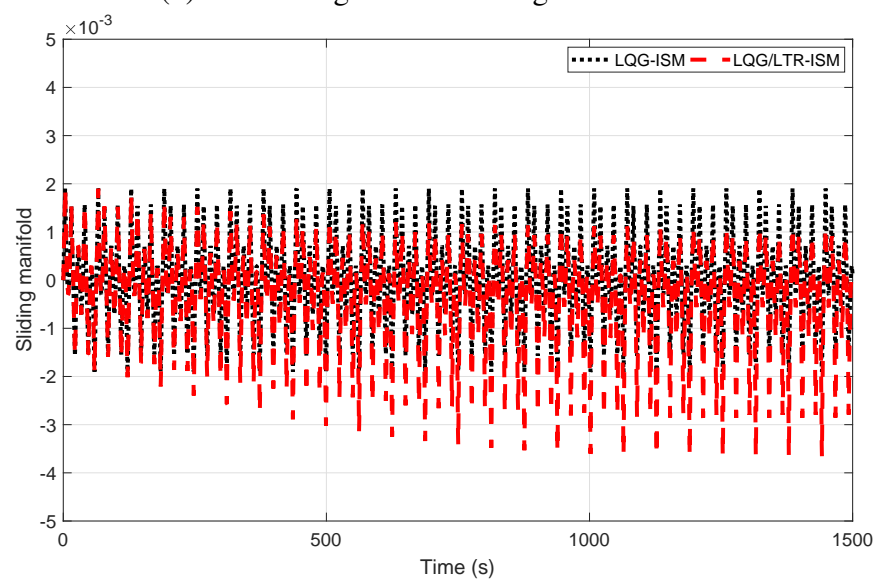

(d) Sliding manifold.

Fig. 9: Variation of turbine speed signals during a set-point change in demand power from generator.

$\begin{array}{ll}l & \text { Pressurizer length }(\mathrm{m}) \\ m & \text { Mass }(\mathrm{kg}) \\ \dot{m} & \text { Mass flow rate }(\mathrm{kg} / \mathrm{s}) \\ p & \text { Pressure }(\mathrm{MPa}) \\ q & \text { Torque }(\mathrm{J} / \mathrm{rad}) \\ z & \text { Speed }(\mathrm{m} / \mathrm{s}) \\ \Lambda & \text { Neutron generation time }(\mathrm{s}) \\ \alpha & \text { Temperature coefficient of reactivity }\left({ }^{0} \mathrm{C}^{-1}\right) \\ \beta & \text { Fraction of delayed neutrons } \\ \kappa & \text { Constant } \\ \lambda & \text { Decay constant }\left(\mathrm{s}^{-1}\right) \\ \rho & \text { Reactivity }(\mathrm{mK}) \\ \zeta & \text { Damping ratio } \\ \tau & \text { Time constant }(\mathrm{s}) \\ \nu & \text { Specific volume }\left(\mathrm{m}^{3} / \mathrm{kg}\right) \\ \omega & \text { Natural frequency of oscillation }(\mathrm{rad} / \mathrm{s}) \\ \text { Subscripts } & \\ c 1, \mathrm{c} 2, \text { cin } & \text { Coolant at node } 1,2 \text { and inlet } \\ d e m & \text { Demand } \\ f & \text { Fuel } \\ f w & \text { Feed-water } \\ h o t, \text { cold } & \text { Hot and cold leg } \\ h p, i p, l p, & \text { High, intermediate, and low pressure steam } \\ i & i^{t h} \text { group of delayed neutron precursor }\end{array}$

lo, $l r \quad$ Logarithmic and Log rate amplifier

$m 1, m 2 \quad$ MTL 1 and 2

$m p 1, m p 2$ Transfer from MTL 1 and 2 to PCL 1 and 2

$m s 1, m s 2$ Transfer from MTL 1 and 2 to SCL

$p \quad$ Pressurizer

$p 1, p 2 \quad$ PCL 1 and 2

pm1, pm 2 Transfer from PCL 1 and 2 to MTL 1 and 2

rod Regulating rod

rxi, rxu Reactor lower and upper plenum

$s \quad$ Steam

ss $\quad$ Steam in secondary lump

$s g$, sgi, sgu Steam generator, inlet, and outlet plenum

spr, sur Spray and surge

$r t d 1, r t d 2 \quad$ RTD 1 and 2

$\operatorname{tg} \quad$ Turbine-Governor

tur Turbine

$w \quad$ Water

ws Water in secondary lump

\section{REFERENCES}

[1] R. M. Edwards, K. Y. Lee, and M. A. Schultz, "State feedback assisted classical control: An incremental approach to control modernization of existing and future nuclear reactors and power plants," Nuclear Technology, vol. 92, no. 2, pp. 167-185, 1990. 
TABLE II: Performance comparison of different control approaches

\begin{tabular}{|c|c|c|c|c|}
\hline Case & Technique & PRMSE & TVI & $\mathcal{L}_{2} N I$ \\
\hline \multirow{4}{*}{ A.1 } & LQG & $2.214 \times 10^{0}$ & $8.730 \times 10^{-2}$ & $2.595 \times 10^{0}$ \\
\hline & LQG/LTR & $3.387 \times 10^{0}$ & $8.610 \times 10^{-2}$ & $2.474 \times 10^{0}$ \\
\hline & LQG-ISM & $9.811 \times 10^{-1}$ & $9.070 \times 10^{-2}$ & $3.132 \times 10^{0}$ \\
\hline & LQG/LTR-ISM & $9.806 \times 10^{-1}$ & $8.216 \times 10^{-2}$ & $3.130 \times 10^{0}$ \\
\hline \multirow{4}{*}{ A. 2} & LQG & $1.084 \times 10^{1}$ & $2.626 \times 10^{-1}$ & $1.959 \times 10^{1}$ \\
\hline & LQG/LTR & $1.343 \times 10^{1}$ & $5.966 \times 10^{-1}$ & $9.341 \times 10^{0}$ \\
\hline & LQG-ISM & $8.487 \times 10^{0}$ & $2.598 \times 10^{-1}$ & $7.590 \times 10^{0}$ \\
\hline & QG/LTR-ISM & $8.484 \times 10^{0}$ & $8.940 \times 10^{-1}$ & $9.350 \times 10^{0}$ \\
\hline \multirow{4}{*}{ B } & LQG & $1.456 \times 10^{2}$ & $2.005 \times 10^{-1}$ & $3.675 \times 10^{0}$ \\
\hline & LQG/LTR & $1.412 \times 10^{2}$ & $6.364 \times 10^{-1}$ & $3.776 \times 10^{0}$ \\
\hline & LQG-ISM & $1.371 \times 10^{2}$ & $1.563 \times 10^{-1}$ & $3.470 \times 10^{0}$ \\
\hline & LQG/LTR-ISM & $1.369 \times 10^{2}$ & $1.688 \times 10^{-1}$ & $3.455 \times 10^{0}$ \\
\hline \multirow{4}{*}{$\mathrm{C}$} & LQG & $1.540 \times 10^{0}$ & $7.815 \times 10^{0}$ & $2.771 \times 10^{1}$ \\
\hline & LQG/LTR & $1.560 \times 10^{0}$ & $7.897 \times 10^{0}$ & $2.788 \times 10^{1}$ \\
\hline & LQG-ISM & $1.804 \times 10^{-1}$ & $6.850 \times 10^{-2}$ & $9.857 \times 10^{0}$ \\
\hline & LQG/LTR-ISM & $1.803 \times 10^{-1}$ & $6.910 \times 10^{-2}$ & $9.856 \times 10^{0}$ \\
\hline \multirow{4}{*}{ D.1 } & LQG & $4.361 \times 10^{-3}$ & $2.561 \times 10^{3}$ & $2.813 \times 10^{5}$ \\
\hline & LQG/LTR & $4.343 \times 10^{-3}$ & $2.562 \times 10^{3}$ & $2.811 \times 10^{5}$ \\
\hline & LQG-ISM & $4.357 \times 10^{-3}$ & $2.537 \times 10^{3}$ & $2.811 \times 10^{5}$ \\
\hline & LQG/LTR-ISM & $4.341 \times 10^{-3}$ & $2.554 \times 10^{3}$ & $2.810 \times 10^{5}$ \\
\hline \multirow{4}{*}{ D.2 } & LQG & $1.600 \times 10^{-2}$ & $1.151 \times 10^{2}$ & $7.337 \times 10^{3}$ \\
\hline & LQG/LTR & $1.602 \times 10^{-2}$ & $1.153 \times 10^{2}$ & $7.335 \times 10^{3}$ \\
\hline & LQG-ISM & $1.593 \times 10^{-2}$ & $6.782 \times 10^{1}$ & $7.326 \times 10^{3}$ \\
\hline & LQG/LTR-ISM & $1.590 \times 10^{-2}$ & $6.783 \times 10^{1}$ & $7.324 \times 10^{3}$ \\
\hline \multirow{4}{*}{ D. 3} & LQG & $3.784 \times 10^{-1}$ & $1.026 \times 10^{2}$ & $4.627 \times 10^{3}$ \\
\hline & LQG/LTR & $3.781 \times 10^{-1}$ & $1.025 \times 10^{2}$ & $4.624 \times 10^{3}$ \\
\hline & LQG-ISM & $3.779 \times 10^{-1}$ & $5.898 \times 10^{1}$ & $4.624 \times 10^{3}$ \\
\hline & LQG/LTR-ISM & $3.777 \times 10^{-1}$ & $5.900 \times 10^{1}$ & $4.622 \times 10^{3}$ \\
\hline \multirow{4}{*}{$\mathrm{E}$} & $\overline{L Q G}$ & $3.706 \times 10^{0}$ & $2.262 \times 10^{1}$ & $2.120 \times 10^{2}$ \\
\hline & LQG/LTR & $3.703 \times 10^{0}$ & $2.260 \times 10^{1}$ & $2.113 \times 10^{2}$ \\
\hline & LQG-ISM & $3.673 \times 10^{0}$ & $2.215 \times 10^{-1}$ & $2.071 \times 10^{2}$ \\
\hline & LQG/LTR-ISM & $3.669 \times 10^{0}$ & $2.263 \times 10^{-1}$ & $2.068 \times 10^{2}$ \\
\hline
\end{tabular}

[2] H. Arab-Alibeik and S. Setayeshi, "Improved temperature control of a PWR nuclear reactor using an LQG/LTR based controller," IEEE Transactions on Nuclear Science, vol. 50, pp. 211-218, 2003.

[3] G. Li and F. Zhao, "Flexibility control and simulation with multi-model and LQG/LTR design for PWR core load following operation," Annals of Nuclear Energy, vol. 56, pp. 179 - 188, 2013.

[4] G. Li, "Modeling and LQG/LTR control for power and axial power difference of load-follow PWR core," Annals of Nuclear Energy, vol. 68, pp. $193-203,2014$

[5] J. Wan and P. Wang, "LQG/LTR controller design based on improved SFACC for the PWR reactor power control system," Nuclear Science and Engineering, vol. 194, no. 6, pp. 433-446, 2020.

[6] S. G. Chi and N. Z. Cho, "H $\infty$ control theory applied to xenon control for load-following operation of a nuclear reactor," Nuclear Technology, vol. 137, no. 2, pp. 127-138, 2002.

[7] H. M. Emara, A. A. Hanafy, M. M. Z. Abdelaal, and S. Elaraby, "A novel, robust control methodology application to nuclear reactors," Nuclear Science and Engineering, vol. 174, no. 1, pp. 87-95, 2013.

[8] G. Li, B. Liang, X. Wang, and X. Li, "Multivariable modeling and nonlinear coordination control of nuclear reactor cores with/without xenon oscillation using $\mathrm{H} \infty$ loop shaping approach," Annals of Nuclear Energy, vol. 111, pp. 82 - 100, 2018.

[9] X. Yan, P. Wang, J. Qing, S. Wu, and F. Zhao, "Robust power control design for a small pressurized water reactor using an $\mathrm{H}$ infinity mixed sensitivity method," Nuclear Engineering and Technology, 2020.

[10] A. Etchepareborda and J. Lolich, "Research reactor power controller design using an output feedback nonlinear receding horizon control method," Nuclear Engineering and Design, vol. 237, no. 3, pp. 268 $-276,2007$.

[11] M. G. Na, I. J. Hwang, and Y. J. Lee, "Design of a fuzzy model predictive power controller for pressurized water reactors," IEEE Transactions on Nuclear Science, vol. 53, no. 3, pp. 1504-1514, 2006.

[12] H. Eliasi, M. B. Menhaj, and H. Davilu, "Robust nonlinear model predictive control for nuclear power plants in load following operations with bounded xenon oscillations," Nuclear Engineering and Design, vol. 241, pp. 533-543, 2011.
[13] G. Wang, J. Wu, B. Zeng, Z. Xu, W. Wu, and X. Ma, "Design of a model predictive control method for load tracking in nuclear power plants," Progress in Nuclear Energy, vol. 101, pp. 260 - 269, 2017.

[14] V. Vajpayee, S. Mukhopadhyay, and A. P. Tiwari, "Data-driven subspace predictive control of a nuclear reactor," IEEE Transactions on Nuclear Science, vol. 65, no. 2, pp. 666-679, Feb 2018.

[15] G. Ansarifar, H. A. Talebi, and H. Davilu, "Adaptive estimator-based dynamic sliding mode control for the water level of nuclear steam generators," Progress in Nuclear Energy, vol. 56, pp. 61 - 70, 2012.

[16] R. K. Munje, B. M. Patre, S. R. Shimjith, and A. P. Tiwari, "Sliding mode control for spatial stabilization of advanced heavy water reactor," IEEE Transactions on Nuclear Science, vol. 60, no. 4, pp. 3040-3050, 2013.

[17] G. R. Ansarifar, M. H. Esteki, and M. Arghand, "Sliding mode observer design for a pwr to estimate the xenon concentration \& delayed neutrons precursor density based on the two point nuclear reactor model," Progress in Nuclear Energy, vol. 79, pp. 104 - 114, 2015.

[18] G. R. Ansarifar and M. Rafiei, "Second-order sliding-mode control for a pressurized water nuclear reactor considering xenon concentration feedback," Nuclear Engineering and Technology, vol. 36, pp. 94-101, 2015.

[19] G. Ansarifar and H. Akhavan, "Sliding mode control design for a PWR nuclear reactor using sliding mode observer during load following operation," Annals of Nuclear Energy, vol. 75, pp. 611 - 619, 2015.

[20] P. V. Surjagade, A. P. Tiwari, and S. R. Shimjith, "Robust optimal integral sliding mode controller for total power control of large phwrs," IEEE Transactions on Nuclear Science, vol. 65, no. 7, pp. 1331-1344, 2018.

[21] R. J. Desai, B. M. Patre, R. K. Munje, A. P. Tiwari, and S. R. Shimjith, "Integral sliding mode for power distribution control of advanced heavy water reactor," IEEE Transactions on Nuclear Science, pp. 1-1, 2020.

[22] S. Banerjee, K. Halder, S. Dasgupta, S. Mukhopadhyay, K. Ghosh, and A. Gupta, "An interval approach for robust control of a large PHWR with PID controllers," IEEE Transactions on Nuclear Science, vol. 62, no. 1, pp. 281-292, 2015

[23] S. Das, S. Das, and A. Gupta, "Fractional order modeling of a PHWR under step-back condition and control of its global power with a robust $P I^{\lambda} D^{\mu}$ controller," IEEE Transactions on Nuclear Science, vol. 58, no. 5, pp. 2431-2441, 2011.

[24] M. N. Khajavi, M. B. Menhaj, and A. A. Suratgar, "A neural network controller for load following operation of nuclear reactors," Annals of Nuclear Energy, vol. 29, no. 6, pp. 751 - 760, 2002.

[25] S. S. Khorramabadi, M. Boroushaki, and C. Lucas, "Emotional learning based intelligent controller for a PWR nuclear reactor core during load following operation," Annals of Nuclear Energy, vol. 35, no. 11, pp. $2051-2058,2008$.

[26] G. Wang, J. Wu, B. Zeng, Z. Xu, and X. Ma, "A nonlinear adaptive sliding mode control strategy for modular high-temperature gas-cooled reactors," Progress in Nuclear Energy, vol. 113, pp. 53 - 61, 2019.

[27] S. M. H. Mousakazemi, N. Ayoobian, and G. R. Ansarifar, "Control of the reactor core power in PWR using optimized PID controller with the real-coded GA," Annals of Nuclear Energy, vol. 118, pp. 107 - 121, 2018.

[28] V. Utkin and J. Shi, "Integral sliding mode in systems operating under uncertainty conditions," in Proceedings of 35th IEEE Conference on Decision and Control, vol. 4, Dec 1996, pp. 4591-4596 vol.4.

[29] R. M. Edwards, K. Y. Lee, and A. Ray, "Robust optimal control of nuclear reactors and power plants," Nuclear Technology, vol. 98, no. 2, pp. 137-148, 1992.

[30] R. Shaffer, W. He, and R. M. Edwards, "Design and validation of optimized feedforward with robust feedback control of a nuclear reactor," Nuclear Technology, vol. 147, no. 2, pp. 240-257, 2004.

[31] G. Ablay, "A modeling and control approach to advanced nuclear power plants with gas turbines," Energy Conversion and Management, vol. 76, pp. 899-909, 2013.

[32] Z. Dong, Y. Pan, Z. Zhang, Y. Dong, and X. Huang, "Model-free adaptive control law for nuclear superheated-steam supply systems," Energy, vol. 135, pp. 53 - 67, 2017.

[33] C. S. Subudhi, T. U. Bhatt, and A. P. Tiwari, "A mathematical model for total power control loop of large PHWRs," IEEE Transactions on Nuclear Science, vol. 63, no. 3, pp. 1901-1911, June 2016.

[34] T. W. Kerlin, Dynamic Analysis and Control of Pressurized Water Reactors. Academic Press, 1978, vol. 14.

[35] M. R. A. Ali, Lumped Parameter, State Variable Dynamic Models for Utube Recirculation Type Nuclear Steam Generators. PhD dissertation, University of Tennessee, Knoxville, 1976. 
TABLE A.1: Typical Parameters of a PWR Nuclear Power Plant

\begin{tabular}{|c|c|c|c|c|c|c|}
\hline $\begin{array}{c}\lambda_{1} \\
1.2437 \times 10^{-2}\end{array}$ & $\begin{array}{c}\lambda_{2} \\
3.05 \times 10^{-2}\end{array}$ & $\begin{array}{c}\lambda_{3} \\
1.1141 \times 10^{-1}\end{array}$ & $\begin{array}{c}\lambda_{4} \\
3.013 \times 10^{-1}\end{array}$ & $\begin{array}{c}\lambda_{5} \\
1.12866\end{array}$ & $\begin{array}{c}\lambda_{6} \\
3.0130\end{array}$ & $\begin{array}{c}\Lambda \\
3 \times 10^{-5}\end{array}$ \\
\hline $\begin{array}{c}\beta_{1} \\
2.15 \times 10^{-4}\end{array}$ & $\begin{array}{c}\beta_{2} \\
1.424 \times 10^{-3}\end{array}$ & $\begin{array}{c}\beta_{3} \\
1.274 \times 10^{-3}\end{array}$ & $\begin{array}{c}\beta_{4} \\
2.568 \times 10^{-3}\end{array}$ & $\begin{array}{c}\beta_{5} \\
7.48 \times 10^{-4}\end{array}$ & $\begin{array}{c}\beta_{6} \\
2.73 \times 10^{-4}\end{array}$ & $\begin{array}{c}\partial T_{\text {sat }} / \partial p_{s} \\
9.47\end{array}$ \\
\hline $\begin{array}{c}H_{f} \\
71.8725\end{array}$ & $\begin{array}{c}H_{c} \\
1.1254\end{array}$ & $\begin{array}{c}\tau_{f} \\
4.376\end{array}$ & $\begin{array}{c}\tau_{c} \\
7.170\end{array}$ & $\begin{array}{c}\tau_{r} \\
0.674\end{array}$ & $\begin{array}{c}\tau_{r x u} \\
2.517\end{array}$ & $\begin{array}{c}\tau_{r x i} \\
2.145\end{array}$ \\
\hline $\begin{array}{c}\tau_{\text {hot }} \\
0.234\end{array}$ & $\begin{array}{c}\tau_{\text {cold }} \\
1.310\end{array}$ & $\begin{array}{c}\tau_{s g u} \\
0.726\end{array}$ & $\begin{array}{c}\tau_{s g i} \\
0.659\end{array}$ & $\begin{array}{c}\tau_{p 1} \\
1.2815\end{array}$ & $\begin{array}{c}\tau_{p 2} \\
1.2815\end{array}$ & $\begin{array}{c}\tau_{p m 1} \\
1.2233\end{array}$ \\
\hline $\begin{array}{c}\tau_{p m 2} \\
1.2233\end{array}$ & $\begin{array}{c}\tau_{m p 1} \\
0.3519\end{array}$ & $\begin{array}{c}\tau_{m p 2} \\
0.1676\end{array}$ & $\begin{array}{c}\tau_{m s 1} \\
0.3519\end{array}$ & $\begin{array}{c}\tau_{m s 2} \\
0.3519\end{array}$ & $\begin{array}{c}\dot{m}_{\text {sor }} \\
2.1642 \times 10^{3}\end{array}$ & $\begin{array}{c}h_{s s} \\
2.7656 \times 10^{6}\end{array}$ \\
\hline $\begin{array}{c}c_{p f w} \\
5.4791 \times 10^{3}\end{array}$ & $\begin{array}{c}U_{m s 1} S_{m s 1} \\
1.7295 \times 10^{8}\end{array}$ & $\begin{array}{c}U_{m s 2} S_{m s 2} \\
3.6312 \times 10^{8}\end{array}$ & $\begin{array}{c}m_{s} \\
2.0518 \times 10^{3}\end{array}$ & $\begin{array}{c}m_{w} \\
1.8167 \times 10^{4}\end{array}$ & $\begin{array}{c}\alpha_{f} \\
-2.16 \times 10^{-5}\end{array}$ & $\begin{array}{c}C_{t g} \\
2.0481\end{array}$ \\
\hline $\begin{array}{c}\alpha_{c} \\
-1.8 \times 10^{-4}\end{array}$ & $\begin{array}{c}\alpha_{p} \\
1.5664 \times 10^{-4}\end{array}$ & $\begin{array}{l}\tau_{r t d} \\
8.2\end{array}$ & $\begin{array}{c}K_{r t d} \\
10.667\end{array}$ & $\begin{array}{c}G \\
14.5 \times 10^{-3}\end{array}$ & $\begin{array}{c}\tau_{1} \\
5 \times 10^{-8}\end{array}$ & $\begin{array}{c}\tau_{2} \\
2 \times 10^{-3}\end{array}$ \\
\hline $\begin{array}{c}\tau_{3} \\
1\end{array}$ & $\begin{array}{c}\tau_{4} \\
1.01\end{array}$ & $\begin{array}{c}K_{l o} \\
1.95692\end{array}$ & $\begin{array}{c}K_{l r} \\
47.065\end{array}$ & $\begin{array}{c}\kappa_{l o} \\
1.1067 \times 10^{10}\end{array}$ & $\begin{array}{c}\zeta_{t g} \\
0.4933\end{array}$ & $\begin{array}{c}\omega_{t g} \\
14.6253\end{array}$ \\
\hline $\begin{array}{l}K_{t g} \\
6.25\end{array}$ & $\begin{array}{l}O_{r v} \\
1.0\end{array}$ & $\begin{array}{c}\tau_{h p} \\
10.0\end{array}$ & $\begin{array}{l}\tau_{i p} \\
0.4\end{array}$ & $\begin{array}{l}\tau_{l p} \\
1.0\end{array}$ & $\begin{array}{l}F_{h p} \\
0.33\end{array}$ & $\begin{array}{c}F_{i p} \\
0\end{array}$ \\
\hline $\begin{array}{c}F_{l p} \\
0.67\end{array}$ & $\begin{array}{l}\kappa_{h p} \\
0.8\end{array}$ & $\begin{array}{c}d_{w} \\
595.6684\end{array}$ & $\begin{array}{c}d_{s} \\
100.9506\end{array}$ & $\begin{array}{c}V_{w} \\
30.4988\end{array}$ & $\begin{array}{c}A_{p} \\
3.566\end{array}$ & $\begin{array}{c}J_{p} \\
5.4027\end{array}$ \\
\hline $\begin{array}{c}l_{w} \\
8.5527\end{array}$ & $\begin{array}{c}l \\
14.2524\end{array}$ & $\begin{array}{c}h_{s p r} \\
1.336 \times 10^{6}\end{array}$ & $\begin{array}{c}h_{w} \\
1.6266 \times 10^{6}\end{array}$ & $\begin{array}{c}h_{\bar{w}} \\
9.7209 \times 10^{5}\end{array}$ & $\begin{array}{c}\nu_{w} \\
1.7 \times 10^{-3}\end{array}$ & $\begin{array}{c}\nu_{s} \\
9.9 \times 10^{-3}\end{array}$ \\
\hline $\begin{array}{c}K_{s} \\
8.1016 \times 10^{7}\end{array}$ & $\begin{array}{c}J_{\text {tur }} \\
5.4040\end{array}$ & $\begin{array}{c}I_{t g} \\
1.99642 \times 10^{5}\end{array}$ & $\begin{array}{c}V_{1} \vartheta_{1} \\
0.5991\end{array}$ & $\begin{array}{c}V_{2} \vartheta_{2} \\
0.1814 \\
\end{array}$ & $\begin{array}{c}V_{3} \vartheta_{3} \\
0.1814 \\
\end{array}$ & $\begin{array}{c}V_{4} \vartheta_{4} \\
1.3164 \\
\end{array}$ \\
\hline $\begin{array}{c}V_{5} \vartheta_{5} \\
0.2752\end{array}$ & $\begin{array}{l}V_{6} \vartheta_{6} \\
2.776\end{array}$ & $\begin{array}{c}V_{7} \vartheta_{7} \\
0.6022\end{array}$ & $\begin{array}{c}V_{8} \vartheta_{8} \\
0.6022\end{array}$ & $\begin{array}{c}V_{9} \vartheta_{9} \\
0.2776\end{array}$ & $\begin{array}{l}V_{10} \vartheta_{10} \\
0.0070\end{array}$ & $\begin{array}{c}T_{f w} \\
232.2\end{array}$ \\
\hline $\begin{array}{c}K_{1 p} \\
-8.152 \times 10^{-3} \\
\end{array}$ & $\begin{array}{c}K_{2 p} \\
4.708 \times 10^{-3} \\
\end{array}$ & $\begin{array}{c}K_{3 p} \\
-1.118 \times 10^{-4}\end{array}$ & $\begin{array}{c}K_{4 p} \\
4.708 \times 10^{-3}\end{array}$ & & & \\
\hline
\end{tabular}

[36] M. Naghedolfeizi, Dynamic Modeling of a Pressurized Water Reactor Plant for Diagnostics and Control. Master's thesis, University of Tennessee, Knoxville, 1990.

[37] L. Wang, W. Sun, J. Zhao, and D. Liu, "A speed-governing system model with over-frequency protection for nuclear power generating units," Energies, vol. 13, no. 173, 2020.

[38] D. S. Naidu, Optimal control systems. CRC press, 2002.

[39] J. Doyle and G. Stein, "Multivariable feedback design: Concepts for a classical/modern synthesis," IEEE Transactions on Automatic Control, vol. 26 , no. 1 , pp. 4-16, 1981.

[40] M. T. Hamayun, C. Edwards, and H. Alwi, Fault tolerant control using integral sliding modes. Springer, Cham, 2016.

[41] C. Edwards and S. K. Spurgeon, Sliding Mode Control: Theory and Applications. Taylor and Francis, 1998. 